An Affirmative Action/Equal Opportunity Employer

This report was prepared as an account of work sponsored by an agency of the

United States Government. Neither the United States Government nor any agency thereof, nor any of their employees, makes any warranty, express or implied, or assumes any legal liability or responsibility for the accuracy, completeness, or usefulness of any information, apparatus, product, or process disclosed, or represents that its use would not infringe privately owned rights. Reference herein to any specific commercial product, process, or service by trade name, trademark, manufacturer, or otherwise, does not necessarily constitute or imply its endorsement, recommendation, or favoring by the United States Government or any agency thereof. The views and opinions of authors expressed herein do not necessarily state or reflect those of the United States Government or any agency thereof. 


\section{DISCLAIMER}

This report was prepared as an account of work sponsored by an agency of the United States Government. Neither the United States Government nor any agency Thereof, nor any of their employees, makes any warranty, express or implied, or assumes any legal liability or responsibility for the accuracy, completeness, or usefulness of any information, apparatus, product, or process disclosed, or represents that its use would not infringe privately owned rights. Reference herein to any specific commercial product, process, or service by trade name, trademark, manufacturer, or otherwise does not necessarily constitute or imply its endorsement, recommendation, or favoring by the United States Government or any agency thereof. The views and opinions of authors expressed herein do not necessarily state or reflect those of the United States Government or any agency thereof. 


\section{DISCLAIMER}

Portions of this document may be illegible in electronic image products. Images are produced from the best available original document. 
LA--11514-MS

DE89 016687

Hot Dry Rock Geothermal Energy -

A New Energy Agenda for the

21st Century

J.W. Tester*

D. W. Brown

R.M. Potter**

*Massachusetts Institute of Technology, Cambridge, MA 02139.

**Consultant at Los Alamos. 
\begin{tabular}{l} 
a \\
\hline
\end{tabular} 


\title{
HOT DRY ROCK GEOTHERMAL ENERGY - A NEW ENERGY AGENDA FOR THE 21st CENTURY
}

\author{
by
}

\author{
J. W. Tester, D. W. Brown, and R. M. Potter
}

\begin{abstract}
Hot Dry Rock (HDR) geothermal energy, which utilizes the natural heat contained in the earth's crust, can provide a widcly available source of nonpolluting energy. It can help mitigate the continued warming of the earth through the "greenhouse effect," and the accelerating destruction of forests and crops by acid rain, two of the major environmental consequences of our ever-increasing use of fossil fuels for heating and power generation. In addition, HDR, as a readily available source of indigenous energy, can reduce our nation's dependence on imported oil, enhancing national security and reducing our trade deficit. The earth's heat represents an almost unlimited source of energy that can begin to be exploited within the next decade through the HDR heat-mining concept being actively developed in the United States and in several other countries. On a national scale, we can begin to develop this new energy source, using it directly for geothermal power or indirectly in hybrid geothermal/fossil-fueled systems, in diverse applications such as

- baseload power generation,

- direct heat use,

- feedwater heating in conventional power plants, and

- pumped storage/load leveling power generation.

This report describes the nature of the HDR resource and the technology required to implement the heat-mining concept in several applications. An assessment of the requirements for establishing HDR feasibility is presented in the context of providing a commercially competitive energy source.
\end{abstract}




\section{MOTIVATION AND SCOPE}

Energy use and its effects on the environment are among the key issues that the United States and other countries must confront and begin resolving during the remaining decade of this century. In this report, we consider several aspects of future energy production as they relate to local and worldwide energy supply and environmental degradation. One critical problem is our large dependence on forcign oil - currently $37 \%$ of our total petroleum budget (Energy Information Administration, 1988). Given our ever-diminishing domestic oil and gas reserves, our dependence will undoubtedly increase even with continuing conscrvation measures. To maintain proper economic stability and alleviate a significant portion of our trade deficit, the US must become more energy independent. Because oil and gas discoveries within the US have not been able to maintain sufficient reserves to supply our current and future needs, other energy sources are needed to achieve this independence. In fact, this shortfall of conventional oil and gas supplies in the US could be a harbinger of future instability that requires a reassessment of national energy policy. Synthetic fucls generated from oil shale and tar sands, gasificd and liquefied coal, and other synthetic fuel sources may provide some relief, but the economics and environmental consequences of their utilization may limit their widespread development in the US.

In addition to the supply issue, continuing studies have shown that 20 th century energy production methods, as well as the direct uses of fossil fuels for heating, industrial, and transportation needs, are having an adverse effect on the environment. Of primary concern are the deleterious cffects that result from the vast amounts of $\mathrm{CO}_{2}$ produced by fossil fuel combustion and smaller amounts of other gases such as $\mathrm{SO}_{2}$ and $\mathrm{NO}_{x}$ that are liberated in the combustion process (Brown et al., 1988; Lovins ct al., 1981; Shcpard, 1988; and Mathews, 1987). These gases play major roles in the processes that causc global warming (the greenhouse effect) and $\mathrm{pH}$ changes in regional precipitation (acid rain). How energy is produced and consumed worldwide is directly related to a most important climatological index, the earth's average temperature. Just as it does in biological systems, this average temperature may determine, to a large degrce, the "hcalth and vitality" of our planet. Because of the uncertainty in predicting changes in the carth's temperature and the resulting consequences, the natural tendency is to minimize change in attempting to preserve the present world state.

It appears that the only practical solution to this dilemma is to significantly reduce the use of fossil fuels in electrical generation, direct thermal applications, and transportation systems. Active conservation programs may be able to achieve additional gains (Chandler et al., 1988), but the real solution seems to lie with the application of altemative energy generation technologies. Many studies have proposed significantly increasing the use of nuclear energy and other nonfossil cnergy options as rapidly as possible. Altcrnative options mentioned typically include solar, fusion, biomass, and wind turbines in the energy generation ficld and direct or indirect electrical methods for transportation necds. Conspicuously absent (at least to the authors of this report) is the inclusion of geothermal encrgy as a potential fossil fuel replacement for a major portion of our future encrgy necds.

\section{THE ROLE OF HDR GEOTHERMAL ENERGY IN OUR NATIONAL ENERGY POLICY}

Geothermal energy, in the form of naturally occurring high-temperature water or steam, is presently providing an economical and trouble-free source of electric energy in a number of locations worldwide. Usually in these natural systems, an interconnected network of open fractures is present through which groundwater can circulate and be heatcd by conduction from the surrounding rock. On a worldwide scale, natural geothermal systems both hot enough and large enough to supply significant baseload encrgy (more than 250 MWe either on-line or under construction) occur in relatively few locations: Indonesia, Northern Italy, Japan, Mexico, New Zealand, the Philippines, and the western US (DiPippo, 1988). Even with distribution limited to the few regions where these hydrothermal anomalies occur, the magnitude of the US resource base is still substantial at some 44,000 quads $^{*}$ of encrgy,

\footnotetext{
* 1 quad $=10^{15} \mathrm{Btu}=1.055 \times 10^{18} \mathrm{~J}=181.8 \times 10^{6}$ barrcls of oil $=3.345 \times 10^{4} \mathrm{MW}-\mathrm{yr}$.
} 
which is the equivalent of 8000 billion barrels of oil [National Research Council (NRC), 1987]. Worldwide, the natural geothermal resource base is estimated to be about 130,000 quads (Armstead and Tester, 1987). In contrast to other alternative energy sources that have yet to be developed commercially, geothermal energy is currently providing over $2200 \mathrm{MWe}$ of baseload electricity in the US and over $5000 \mathrm{MWe}$ worldwide (DiPippo, 1988). In many other areas, geothermal energy is used directly for heat. For example, it currently provides about $1700 \mathrm{MWt}$ in the US alone (Lienau et al., 1988). In the short term, natural systems will continue to be exploited because they provide an economically and environmentally acceptable alternative to fossil fuels and nuclear energy.

However, of greater ultimate importance is the feasibility of extracting much larger amounts of geothermal energy from accessible regions of hot rock beneath the earth's surface that do not contain sufficient natural porosity or permeability. As depicted in Fig. 1, energy can be extracted from artificially fractured rescrvoirs that emulate natural geothermal systems. The primary technique for enginecring these so-called Hot Dry Rock (HDR) geothermal reservoirs utilizes fluid pressure to open and propagate fractures from an inclined well, creating artificial permeability within a fracture network (Fig. 1). This hydraulically stimulated region is then connected to a second well to complete the underground system. Heat is extracted by circulating water from the surface, down one wcll, through the fractured rock network, and up the second well. The heated water then passes through an appropriatcly designed power plant on the surface where, for instance, electricity or process steam is generated. The coolcd fluid is then reinjected to complete a closed-loop cycle. Thus, effluents from HDR systcms are practically

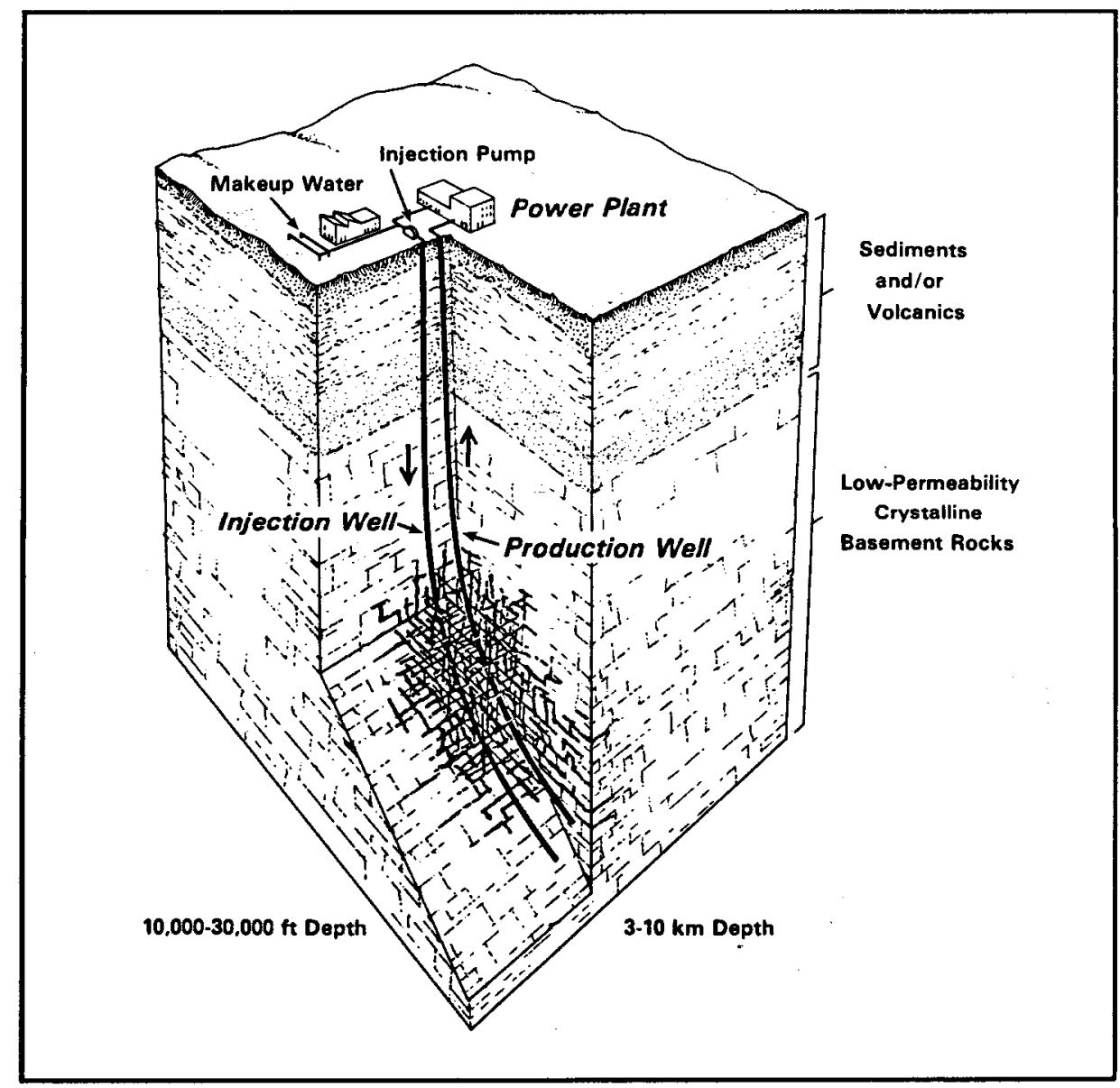

Fig. 1. Hot dry rock (HDR) geothermal system concept for low-permeability formations. 
nonexistent. In effect, we would be mining heat in a fashion analogous to the way other resources are obtained (Smith et al., 1975; Armstead and Tester, 1987).

Because Hot Dry Rock systems do not require contained hot fluids and high permeability, the HDR resource - the accessible thermal energy in the earth's crust - is much larger and more widely distributed than natural geothermal systems. Numerous estimates place the accessible HDR resource base somewhere between 10 and 13 million quads in the US and over 100 million quads worldwide (see Appendix A for details). Accessible is defined as the nominal depth presently attainable using conventional drilling technology (about $10 \mathrm{~km}$ ). Figure 2 provides estimates of the geothermal temperature gradient distribution across the US and clearly shows that the moderate-grade $\left(30^{\circ}\right.$ to $\left.45^{\circ} \mathrm{C} / \mathrm{km}\right)$ HDR resource is well distributed. Recent studies by Kron and Heiken (1980) estimate the high-grade US HDR resource base, with gradients greater than $45^{\circ} \mathrm{C} / \mathrm{km}$, to be in excess of 650,000 quads. Thus, on almost any basis, the amount of potentially usable thermal energy in the HDR resource is vast - literally orders of magnitude larger than the sum total of all fossil and fissionable resources (see Fig. 3 for a comparison on a worldwide basis). Even if only a small fraction of the accessible HDR resource base is ultimately extracted, the impact on the US energy supply would be far-reaching. In fact, it is this great potential for HDR that has encouraged many to advocate its inclusion as a major component of the US energy development program (Armstead, 1983; NRC, 1987).

For the past 16 years, Los Alamos National Laboratory has conducted a major research effort to develop techniques for creating such reservoirs in essentially impermeable hot crystalline rock under sponsorship of the US Department of Energy (USDOE). The Federal Republic of Germany and the Government of Japan have supported a portion of this work under a collaborative agreement with the US. In addition to the US effort, the British have been involved in the development of HDR technology for about 10 years at a site in Cornwall (Batchelor, 1984). The US program, described in greater detail in Appendix B, already has successfully met most of the crucial technical goals (listed below) that are required before large-scale HDR geothermal energy development can occur.
- Accessibility to the Resource - Conventional oil and gas drilling methods and capabilities have been successfully adapted to the harsh environment encountered at depth in hard crystalline rock where useful temperatures (about $150^{\circ}$ to $300^{\circ} \mathrm{C}$ ) are found.

- Creation of Usefully Large Fracture Systems - Again, oil industry methods of hydraulic stimulation have been successfully adapted to this harsh environment, resulting in the development of permanently opened and connected fracture systems contained within very large volumes of hot crystalline rock.

- Efficient Extraction of Thermal EnergyThe heat extraction process in these fracture systems has been shown to be both predictable and suitable for commercial use.

- Determination of the Size and Physical Structure of the Created Fracture System Acoustic emissions accompanying the creation of these fracture systems have been used successfully to determine location, size, and orientation of the fractured and interconnected region (i.e., the HDR reservoir).

At present, most of the HDR R\&D field efforts are concentrated at two locations: at the Fenton Hill site in northem New Mexico in the United States, and at the Rosemanowes site in Cornwall in the southwestern region of the United Kingdom. However, useful work on a smaller scale is also being done in Japan, France, and the USSR, but it is too early to forecast the effect of their research on this emerging technology. In the United Kingdom, following testing at the Rosemanowes site, a deeper, hotter commercial-scale heat extraction test is being considered at some suitable location within the Carmenellis granite of Cornwall.

Realistically, however, the future of HDR technology development in the US, at least in the decade ahead, seems to lie solely with the success of reservoir testing at the Fenton Hill experimental site in northern New Mexico. Unfortunately, with a decreasing Federal budget for advanced energy research within the USDOE, funding to develop the potentially large HDR resource has become inadequate (NRC, 1987). Over the past 16 years, pioneering field efforts at Fenton Hill have provided the basis for developing the necessary stimulation 


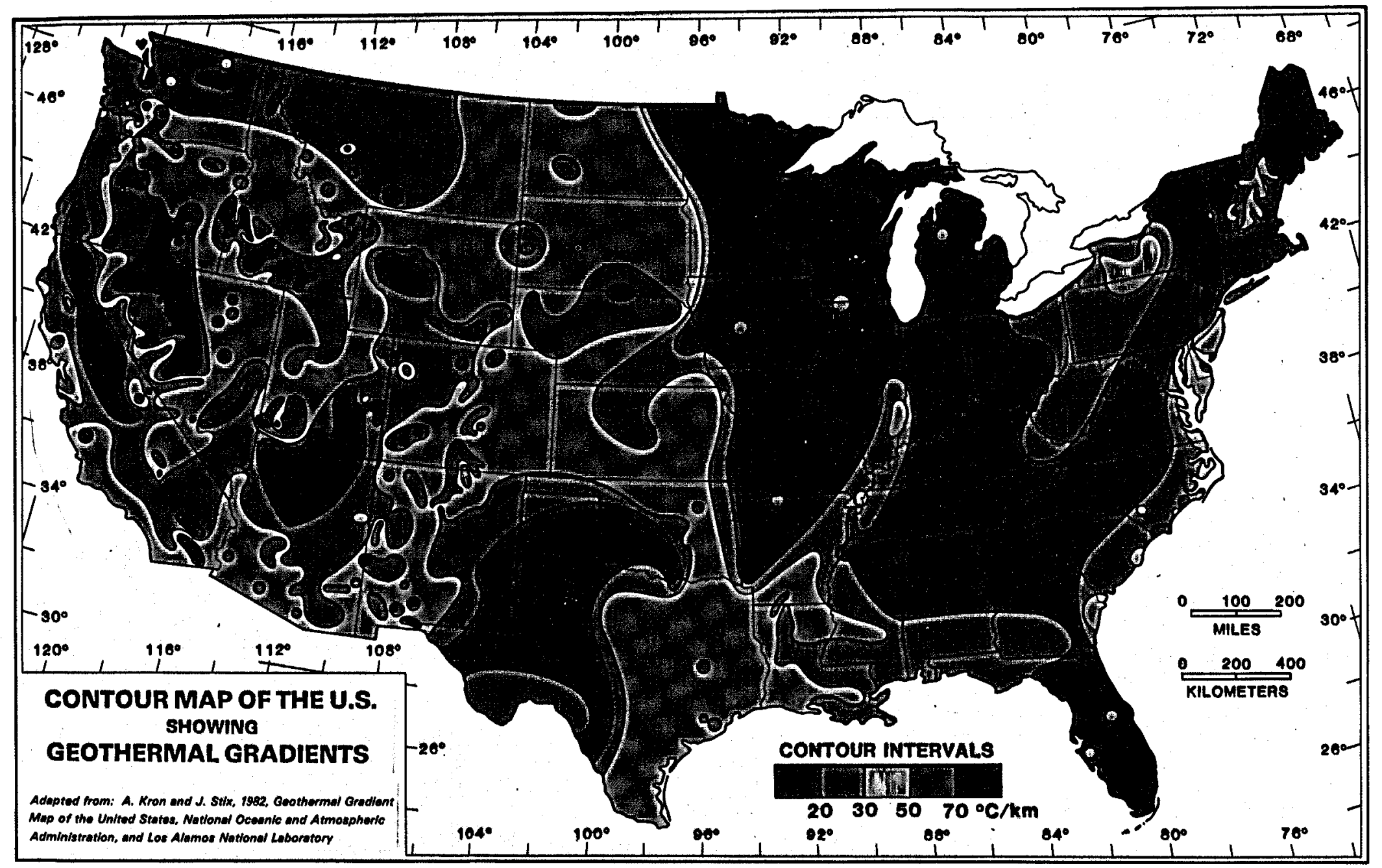

Fig. 2. Geothermal temperature gradient distribution across the US. 


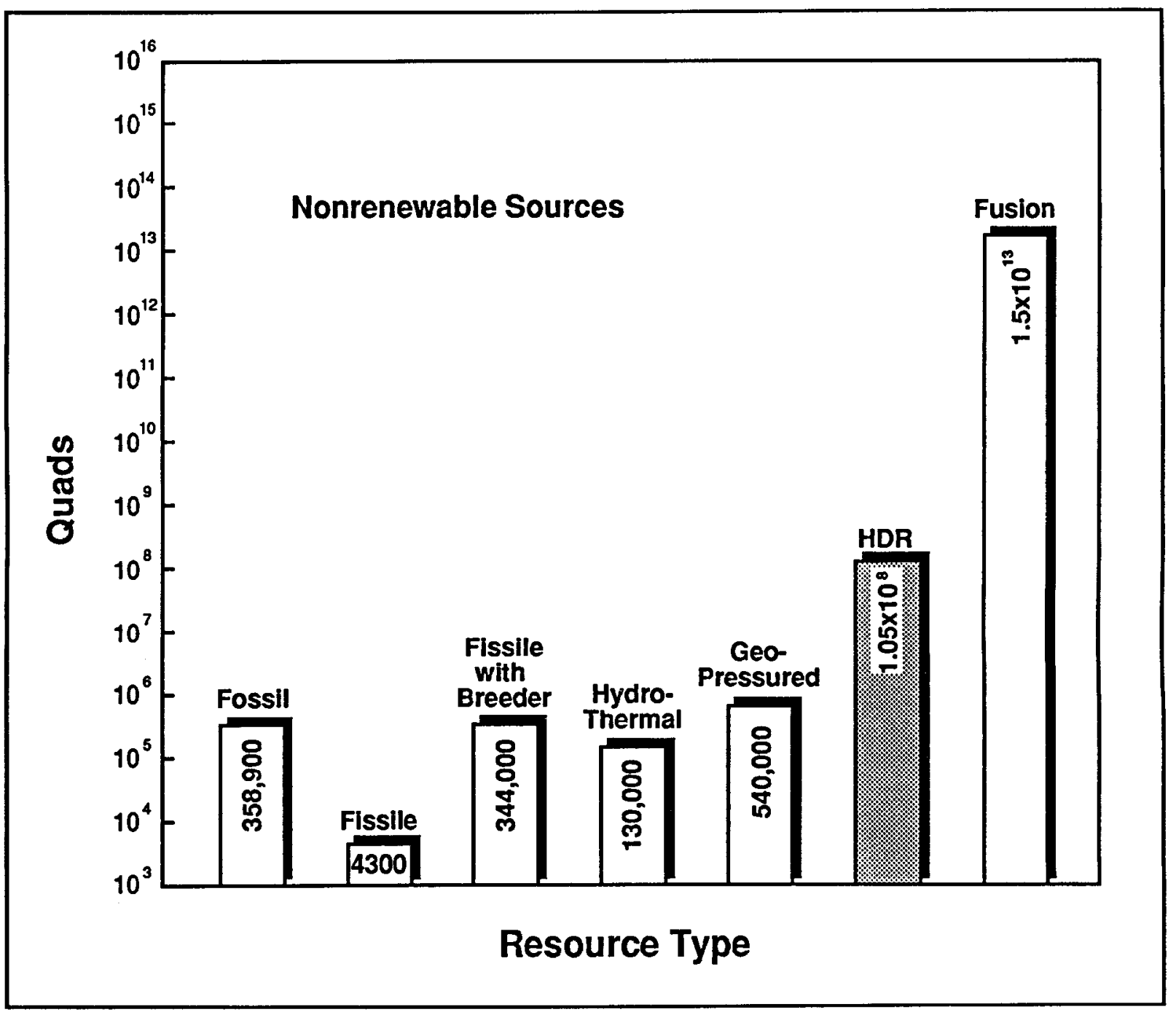

Fig. 3. Worldwide resource base estimates for nonrenewable resources (adapted from Armstead and Tester, 1987).

and extraction technologies. However, these achievements in the field, and remaining technical and economic barriers, need to be re-evaluated with a more farsighted perspective. In considering these issues, the roles of government and industry need to be determined to promote further development of HDR. For example, what level of funding from public and private sources should be allocated to HDR research and development? The potential of HDR as a major nonfossil component of the US energy supply in the next century should be carefully compared with that of other resources of similar magnitude, such as fusion and solar.

We believe the best overall national energy policy, regarding altemate energy development programs, to be one that allocates the available government funding based on two criteria: (1) the potential magnitude of the resource and (2) the time scale for its implementation. Adherence to such a policy would imply a continuing strong role for the government during the next phase of HDR development. During this phase, industry would be involved in constructing and testing several HDR demonstration systems at geologically different sites, which would provide the private sector with sufficient experience and data for large-scale HDR commercialization.

New HDR development sites, in addition to Fenton Hill, should be considered for funding as a part of the USDOE program. These should include high-grade 
sites such as the Geysers/Clear Lake region in California or Roosevelt Hot Springs in Utah for electric power generation, and lower-grade HDR sites in the eastern US for integrated combined-cycle cogeneration and/or directheat applications.

With increased government support, one or more commercial-scale HDR developments could be in fullscale operation during this century. Given today's economic climate, however, the level of government funding for these follow-on HDR projects at new sites will approach $100 \%$ of the total development costs.

Specific recommendations for HDR funding have been made by the Advanced Resources Program panel and by a panel on geothermal technology convened by the National Research Council (NRC, 1987) that reviewed the geopressured, hot dry rock, and magma components of the USDOE's geothermal program. They concluded that the Federal Government should continue to support the Los Alamos project through its planned long-term flow test at Fenton Hill, and that a second site should be developed through the demonstration stage of a 5- to 10-MWe power plant. Completion of Fenton Hill testing will require about $\$ 34$ million, and the second site development about $\$ 72$ million.

Within the next decade or two, a growing number of government-supported HDR projects may catalyze privately funded developments in much the same way fission reactors were developed in the post-World War II era with substantial Federal subsidy. Under these assumptions, HDR, as a new energy source, could assume a significant role in supplying the country's energy needs during the 21 st century.

We believe that HDR energy, with its unique characteristics, could be a major extender of and replacement for fossil-fuel thermal energy, providing the following benefits:

- Minimal Environmental Impact - No fluids or gases are released to the environment because HDR systems operate in a closed-loop circulation mode (not unlike an automobile engine's cooling system). Thus, HDR geothermal energy will not contribute to increased levels of atmospheric $\mathrm{CO}_{2}$. Natural geothermal systems on the other hand, depending on the specific characteristics of the resource and the surface plant design, may emit some $\mathrm{CO}_{2}$. However, as shown in Fig. 4, the ranges of $\mathrm{CO}_{2}$ emission per unit of energy for hydrothermal systems are significantly lower than the amounts generated from fossil-fuelbased technology. Further, waste heat rejected from HDR electric power plants will be so widely dispersed that its effect on any local environment will be minimal. Finally, drilling access wells and laying pipelines may temporarily disturb the land surface, but obviously such changes will be on a much smaller scale than those associated with strip mining coal for instance.

- High Availability and AccessibilitySimply stated, HDR energy is available virtually everywhere on the earth's surface, with the resource temperature inexorably increasing with depth. However, the actual quality or grade of the HDR resource at a specific location will control development costs. The primary parameter determining the local grade of the resource is the average temperature gradient or conversely the drilling depth required to reach a temperature suitable for the specified application.

- Readily Usable as Produced in Baseload Applications - HDR production is in the form of hot water under pressure, which can be used directly for local space or process heating needs, or for lower-temperature power plant heat requirements. HDR can be used as a single supply of energy to a power plant, or used in conjunction with coal, oil, or natural gas in a hybrid plant to improve efficiency. In the first case, fossil fuel consumption and $\mathrm{CO}_{2}$ generation rates per unit of electricity produced are entirely eliminated, and in the second case, they are significantly reduced.

- Applicable to Pumped Storage Use of Off-Peak Electric Power - Because of their elastic nature, HDR reservoirs can be utilized for off-peak pumped storage, with the potential for increasing the effective size of our domestic electric generating capacity. The stored fluid is returned as heated water that can be used in hybrid power plants to produce more power than was used in the storage process, representing a major advance over other pumped storage concepts. In this sense, HDR pumped storage is essentially an "electric power multiplier."

- Each Reservoir Represents a Large Thermal Resource - Field experience has shown 


\section{Millions of Tons of Carbon, as $\mathrm{CO}_{2}$ Emitted per Quad (10 15 BTU)}

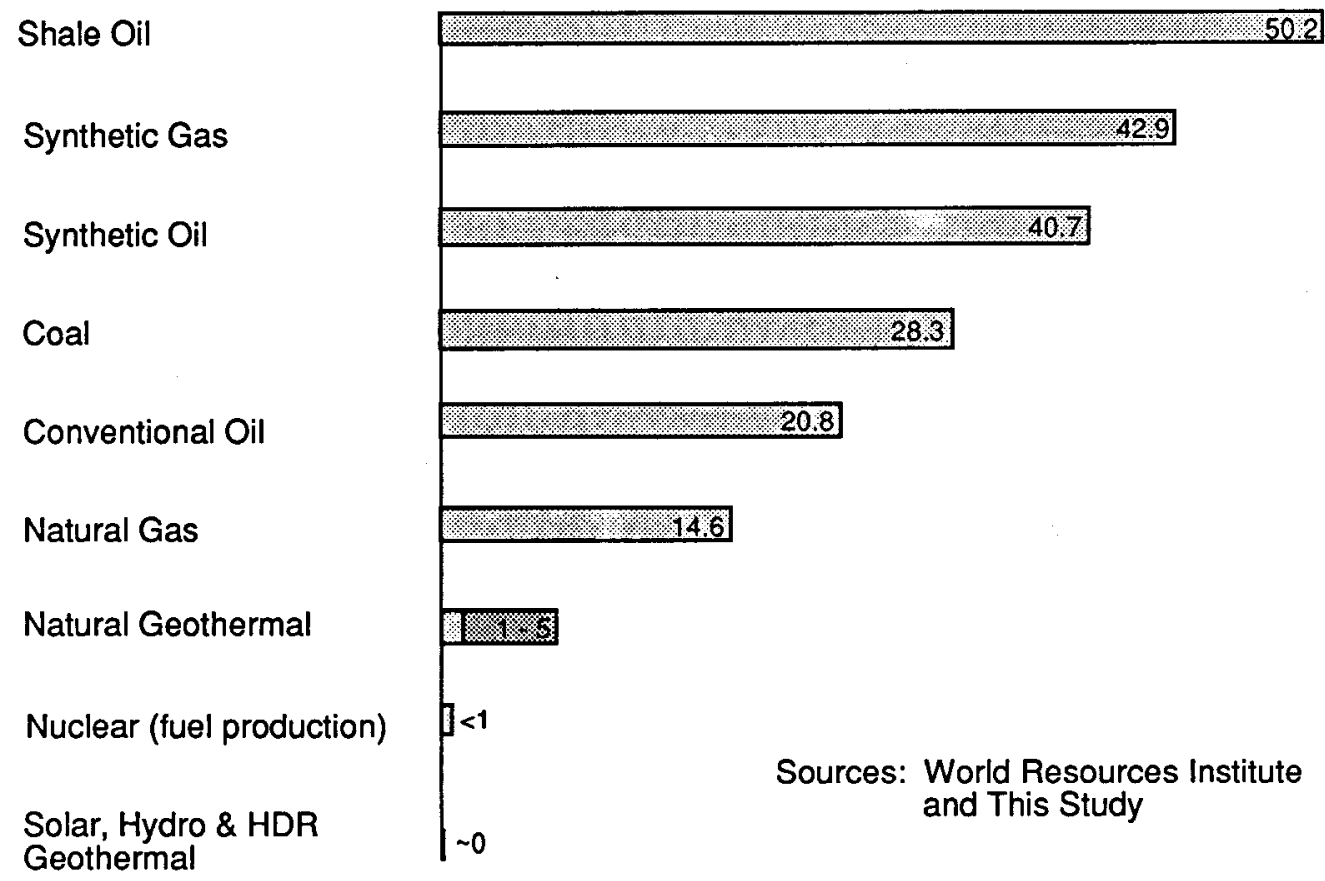

Fig. 4. Carbon dioxide emitted per quad of thermal energy produced for different fuel sources (adapted from Hamilton, 1988).

that fractured HDR rescrvoirs can be created economically and that their size can be almost arbitrarily large, depending primarily on the volume of injected water. For example, by increasing reservoir size, one can provide for multiple cogencration needs by producing both power and process heat, with only a very modest increase in reservoir development costs.

The story is not complete with just a description of these positive attributes; there is a negative side that has restricted the widespread development of HDR. Two major barriers remain as constraints to commercialization: (1) a demonstration that reservoirs of sufficient size and lifetime can be created to maintain economic fluid production rates and (2) a reduction in the relatively high costs of drilling wells in hard crystalline rock. HDR energy supply costs are inherently linked to a combination of these factors. For example, a key economic parameter is the cost of producing a unit of fluid at a specified temperature. This can be expressed in $\$ / \mathrm{kg} / \mathrm{s}$ of fluid produced or in $\$ / \mathrm{kW}$ of thermal power. Higher reservoir flow rates per wcllpair and/or lower individual well drilling costs reduce the overall cost of supplying HDR energy. On the other hand, higher flow rates through the reservoir tend to accelerate thermal drawdown, as thermal energy is removed from the rock at a rate higher than it can be replenished.

Economic feasibility of HDR depends on finding satisfactory solutions to these constraints. Data collected during field testing in the US and UK suggest that, by vigorously applying and extending existing technology in the area of reservoir development and drilling, tractable solutions are within reach. In fact, much progress has been made already as is described in the next section. Assuming these issues have becn resolved, HDR geothermal energy can play an early and substantial role in national policies directed toward reducing fossil fuel use. As an abundant but low-temperature energy source, one probable use will be to 
preheat working fluids used in the electric generating process. However, of much greater importance is the potential for HDR in supplanting significant quantities of natural gas and heating oil now used for space heating and lower-temperature industrial processes. This application of HDR geothermal energy will assist in preserving our more limited quantities of high-grade fuels (of high thermodynamic potential) for use in hightemperature industrial processes, for transportation, and in electric power generating systems operating at high conversion efficiency (40\%-50\%). In this mode, HDR could more than double the lifetime of our domestic reserves of petroleum and natural gas.

An HDR reservoir temperature of $85^{\circ} \mathrm{C}$ is sufficient for direct-use space heating needs (Armstead and Tester, 1987). In the eastern US, this temperature level can normally be reached by drilling to 3 to $4 \mathrm{~km}$. An HDR direct-heat utilization program from these depths could be developed on a national scale within a reasonably short time by utilizing the excess capacity of our depressed oil drilling industry (only about 770 operating drilling rigs as of Spring 1989 vs 4530 in 1981). New home subdivisions and/or new industrial complexes could provide a ready space-heating market to drive the development of the HDR resource, particularly with favorable tax incentives.

In addition to these immediate direct-heat uses, a substantial future role in the generation of electricity from the broadly distributed lower-grade HDR resource is possible. Advances in hard-rock drilling technology during the next decade should permit the economic drilling of HDR boreholes to depths of $10 \mathrm{~km}$, which is now the maximum depth for oil and gas wells. This would ensure that rock temperatures in excess of $200^{\circ} \mathrm{C}$ - appropriate for HDR-augmented electric power generation - will be accessible almost everywhere in the US and not just limited to high-gradient areas.

Thus, the ubiquitous HDR resource is ideal for more diffuse, less concentrated clectric power and thermal energy production. The resulting dispersion of energy production, if HDR were introduced on a national scale, could be of great practical and sociological importance, helping to ameliorate past environmental and social problems resulting from the use of megasized power plants, which are often sited near population centers. HDR, by providing inexpensive electrical and thermal power for smaller communities and asso- ciated industries, and thus by dispersing jobs and population, might be a strong force in revitalizing the nation.

It is unlikely that a single energy source or system can adequately meet all of the nation's or the world's energy needs. However, the HDR resource, with its tremendous range of thermal grade and relatively straightforward implementation technology, can be drawn upon in increasingly sophisticated ways to provide, directly and in concert with other fossil and nonfossil thermal sources, much of our energy needs for thousands of years.

The remaining sections of this report and the appendixes provide the documentation to substantiate our claims. Further detail can be obtained from other publications that are cited in the forthcoming sections. For general treatments of the technology, see especially Smith et al. (1975); Murphy et al. (1982); Tester et al. (1979); Armstead and Tester (1987); and Cummings and Morris (1979).

\section{ENGINEERING FEASIBILITY ISSUES FOR HDR}

Unlike hydrothermal or geopressured resources that require indigenous hot fluids, hot dry rock systems need only hot rock at accessible depths in the earth's crust. HDR resources range from low-grade regions having normal to near-normal temperature gradients of $20^{\circ}$ to $40^{\circ} \mathrm{C} / \mathrm{km}$, to high-grade regions with above-normal gradients greater than $40^{\circ} \mathrm{C} / \mathrm{km}$. The lower-grade resource is distributed more or less uniformly throughout the US as shown in Fig. 2, while the higher-grade resource is found mostly in the West, frequently within or near active natural geothermal systems.

For the HDR concept to work in practice, the underground system must be properly engineered. A large, open, fractured reservoir must be created, providing artificial permeability where it does not exist naturally, to permit efficient heat extraction by the circulating water. In addition, optimally placed well(s) that maximize the efficiency of the heat-mining process must access the reservoir from the surface. Controlled drilling and reservoir stimulation methods in hot crystalline rock are necessary to properly engineer an HDR system. Many of the technical components needed to 
implement a vigorous national HDR development program are already in place. As mentioned previously, the US program in New Mexico has demonstrated that we can efficiently drill hard crystalline rock using current technology, to temperatures above $300^{\circ} \mathrm{C}$ and depths of $5 \mathrm{~km}$, and that conventional hydraulic stimulation techniques can routinely create multiply fractured HDR reservoirs in deep, jointed, crystalline rock. Further, scientists at the Los Alamos National Laboratory in the US and the Camborne School of Mines in the UK have recently perfected microseismic techniques that can accurately map the three-dimensional envelope of the pressure-stimulated region and can discern major features of its internal structure. A summary of the field testing programs is presented in Appendix B.
Although deep drilling in hard rock is now more or less routine, it is still a slow and costly process using conventional methods. Early data from HDR field drilling in the US and UK suggest that well costs strongly depend on depth, but costs are 2 to 3 times higher for HDR drilling than they are for oil and gas wells (Fig. 5). The drilling programs at Fenton Hill in the mid 1970s represented, at that time, the most extensive deep granitic drilling effort anywhere in the world. However, repeated drilling stops for geophysical measurements, coring, fracturing tests, and diagnostic logging and the lack of industry experience in this hostile drilling environment made overall well costs significantly higher than those for conventional oil and gas drilling. In addition, the even deeper and highly deviated

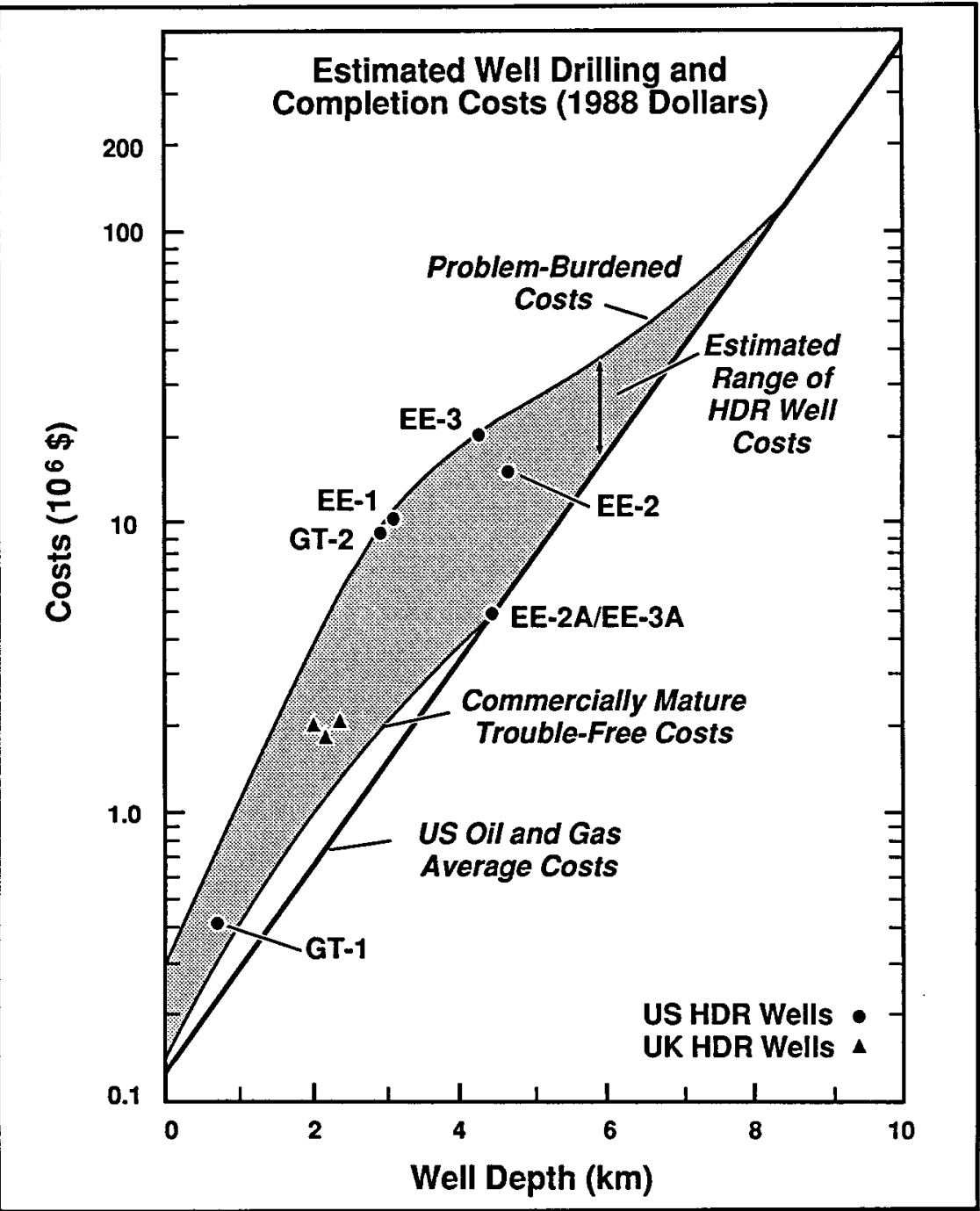

Fig. 5. HDR well drilling costs compared with oil and gas well drilling costs to the same depth. 
drilling programs at Fenton Hill in 1979 and 1980 were plagued (particularly wellbore EE-3) with drilling assembly and drill string fatigue and other materials problems. As a consequence, and again because these deeper drilling programs were also research oriented, costs were 3 to 4 times higher than costs for conventional drilling to the same depth. Fortunately, most of the problems associated with deep granitic drilling have now been resolved, as evidenced by the Laboratory's successful redrilling programs at Fenton Hill in 1985 and 1987 (see EE-2A/EE-3A on Fig. 5, for example). These redrilling programs are discussed in more detail in Appendix C, Section II.

Depending on the geologic setting and rock type, many different geothermal reservoir stimulation methods are possible. However, the US HDR program has focused on engineering systems in regions of deep, hot crystalline rock of low initial permeability and porosity. The primary technique utilizes fluid pressure to open and propagate fractures in the rock surrounding a deep interval in an initial well. This hydraulically stimulated region of high artificial permeability, comprising an interconnected array of dilated joints and fractures, is referred to as the HDR reservoir. As illustrated in Fig. 1, this hydraulically stimulated region is then accessed by optimally drilling a second well to complete the underground system.

The major technical challenges for HDR center on proper engineering of the underground fracture network, which must maximize the heat extraction capacity while minimizing pressure and fluid losses. This requires creation of a large, open, fracture labyrinth that allows fluid to sweep efficiently through a significant volume of hot rock. As heat transport in these systems is inherently limited by the low thermal conductivity of the rock matrix, rock-fluid heat transfer surface areas need to be large. Per pair of wells, these areas must effectively approach 1 million square meters with accessible reservoir volumes of approximately 500 million cubic meters to sustain heat production rates at commercially viable levels of 40 to $50 \mathrm{MWt}$ for a 20 to 30-year system lifetime (Armstead and Tester, 1987; Batchelor,1984; Cummings and Morris, 1979). Pressure drops resulting from pumping fluid through the wellbores and fracture system must also be minimized to reduce parasitic power losses. Furthermore, excessive water losses to the rock surrounding the active reservoir must be avoided. A seismic risk of low order may exist as a result of long-term water loss under pressurized conditions. However, seismic monitoring under long-term pressurized reservoir circulation conditions at both Fenton Hill and Rosemanowes has shown that induced levels are very low. During initial hydraulic stimulations, event magnitudes higher than Richter +1 magnitude have never been observed, and during subsequent circulation tests, all events have been below a magnitude -1 , with aseismicity the norm. Even during initial high-pressure stimulation, the largest of these recorded events have been several orders of magnitude below the level of even a minor earthquake (i.e., one that is just barely felt at the surface).

Further detail on engineering feasibility is found in Appendix C, where demonstrated components of the technology and remaining tasks are outlined.

\section{HDR AS A MEANS TO OPTIMIZE THE USE OF FOSSIL RESOURCES}

We must learn to utilize fossil fuels more efficiently to provide for future needs and to preserve the quality of life at home and worldwide. Currently, petroleum fluids provide the only practical transportation fuel and are a major petrochemical feedstock. Therefore, we must extend their usefulness in these areas by increasing engine efficiency and minimizing petroleum use in the generation of electricity, thereby conserving these valuable, finite resources. Also, to limit - and eventually reverse - the apparent slow warming of the earth through the greenhouse effect, we need to produce the maximum amount of energy for the least amount of evolved $\mathrm{CO}_{2}$. Referring to Fig. 4, natural gas would be the fossil fuel of choice, bettered only by the nonfossil energy sources cited.

Heat extraction from HDR reservoirs, like other geothermal systems, can be on a continuous basis, making them well suited for baseload electric and nonelectric (process heat) applications. However, the inherent mechanical elasticity of a fractured HDR reservoir suggests that cyclic or peaking operation may also be practical. A very important fact to remember is that the temperature and therefore the "thermodynamic grade" of an HDR system can be selected by design based on economic and end use considerations. This is funda- 
mentally different from natural geothermal systems, where fluid temperatures are set $a$ priori by hydrogeologic conditions.

The optimal geofluid temperature selected for a specific application depends on the local temperature gradient, drilling costs, and proposed use. From the many possibilities for using the HDR resource, five concepts have been selected for comparison that represent a range of uses with reasonable utilization efficiencies.

- Hybrid Steam Cycle with HDR Geofluid Feedwater Preheating - In a conventional fossil-fueled steam power plant, HDR geothermal energy would supply the lower-temperature feedwater heating requirements, typically replacing all but the last stage of regenerative feedwater heating.

- HDR-Augmented Combined Gas Turbine Cycle - Most (or all) of the feedwater heating requirements for the turbine-exhaust-driven bottoming steam cycle portion of the combined gasturbine cycle would be supplied by the geofluid, in a manner analogous to the hybrid steam cycle concept above.

- HDR Direct Heat Use - The geothermally heated fluid would be used, either directly or through a heat exchanger, for process or space heating.

- HDR Baseload Electric Power Generation The geofluid would be used to generate power in either a dual-flash or a binary cycle.

- HDRALPS: HDR-Augmented Liquid Pumped Storage - This power-peaking and load-leveling concept gives an electrical energy storage multiplier greater than one. Excess offpeak baseload power would be used to inject fluid into the HDR reservoir, with either a cyclic or a continuous geofluid production flow.

These concepts are described in detail and illustrated schematically in Appendix D. At this point, a few summarizing statements can be made.

To achieve high efficiency, proper matching of the energy source to its end use is of primary importance. In effect, we should use our lower-grade energy sources - solar and geothermal in particular - for lower-grade heating needs and should reserve our fossil fuels for more appropriate higher-temperature applications. Figure 6 shows the US energy consumption as a function of the utilization temperature. Of the almost 80 quads consumed annually in the US, about 20 quads are used for industrial, commercial, and residential heating applications at or below $150^{\circ} \mathrm{C}$ - a temperature level appropriately supplied from our vast and broadly distributed reserves of HDR geothermal energy.

However, the HDR resource is of even higher quality in portions of the western US, approaching the range of $250^{\circ}-300^{\circ} \mathrm{C}$ at economically accessible drilling depths. In these regions, the HDR resource could be used directly to supply both baseload electrical power and process heat (or steam), in whatever mix would be appropriate for a specific application. Or, in a combined power cycle with a fossil-fueled boiler and superheater, HDR geothermal energy could be used to replace up to $20 \%$ of the combined-cycle heat load - saving fuel, reducing $\mathrm{CO}_{2}$ emissions, and increasing the effective efficiency of both the fossil and the HDR energy conversions into electricity.

Even in the eastern US where the average gradients are lower, this hybridized, combined-cycle use of an HDR heat source, typically available at temperatures of $140^{\circ}$ to $170^{\circ} \mathrm{C}$, could displace up to $15 \%$ of the fossil fuel requirements for generating electricity (City of Burbank, 1977). Although the quantitative impact would depend on the source and type of fossil fuel displaced, the application of HDR would have a positive effect, both economically and environmentally. Combined with the direct heat use of HDR energy, a significant portion of the country's energy needs could ultimately be supplied from our broadly distributed HDR resource.

\section{ECONOMICS OF HDR SYSTEMS COMPARED WITH ALTERNATIVES}

The major economic issues for HDR are similar to those for natural geothermal systems in that drilling and completion costs are usually the largest cost components for both. In addition, power plant capital costs are expected to be comparable with those for binary cycle or multistage flash plants designed for low-salinity, liquid-dominated hydrothermal brines ranging in temperature from $200^{\circ}$ to $300^{\circ} \mathrm{C}$. Costs for above- 


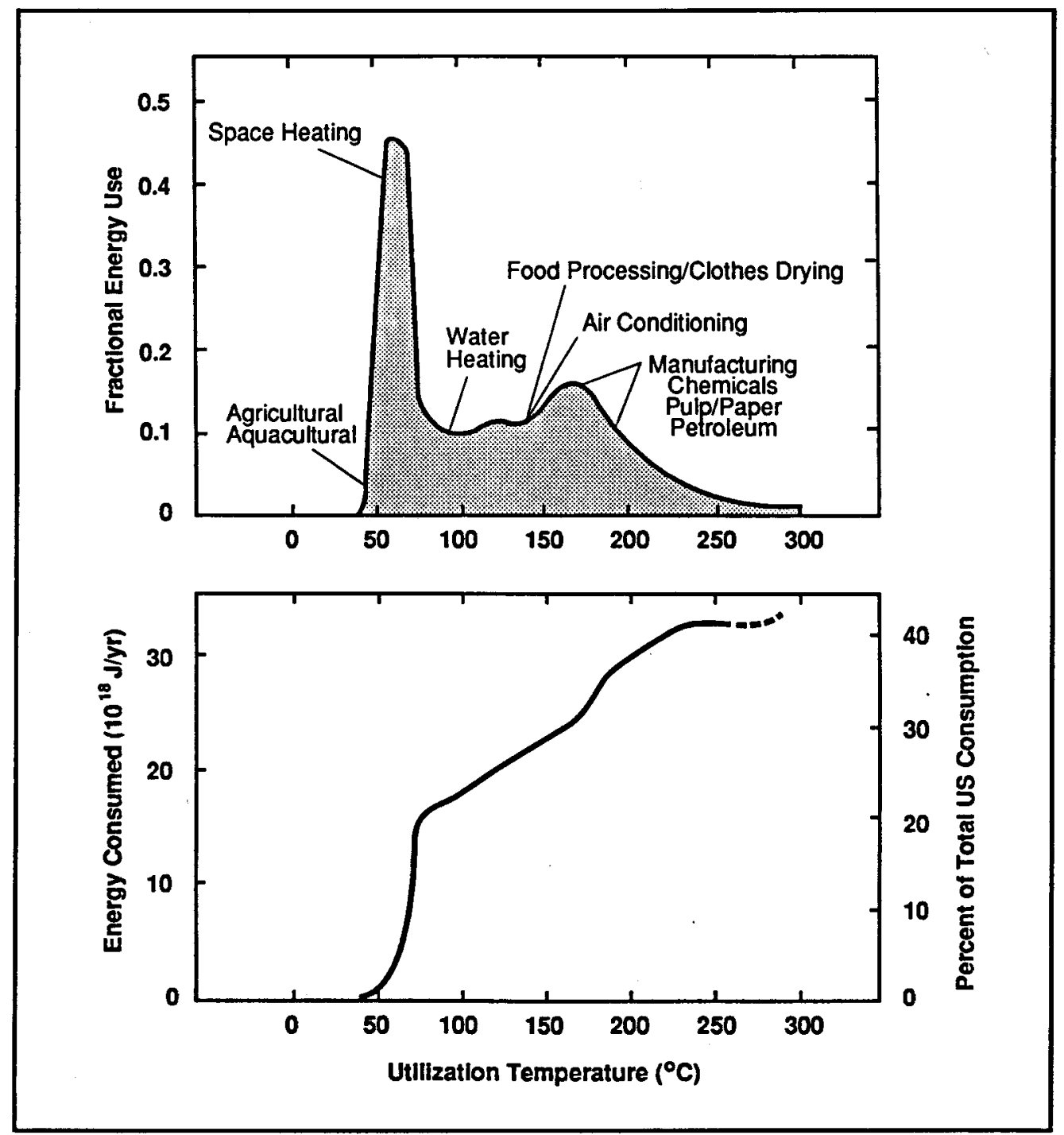

Fig. 6. Distribution of energy use in the US as a function of utilization temperature.

ground equipment and piping for direct heat uses should also be comparable with those for hydrothermal systems. Aside from the investment problems associated with raising equity capital and securing loans from the private sector for commercial HDR development, two primary factors control the cost of producing electricity or heat from HDR. The first is the grade of the resource, which can be quantitatively represented by the effective geothermal gradient. This resource factor strongly influences drilling costs. The second is the productivity of the reservoir, which is defined by several reservoir performance parameters including initial fluid temperature, flow impedance, mass flow rate per pair of wells, and the thermal drawdown rate. The initial fluid temperature for a given HDR resource can be selected by drilling to a certain depth with a defined gradient, whereas the drawdown rate will depend on a single loading parameter, the effective heat transfer surface divided by the mass flow rate. Minimal drawdown rates are desirable, but they cannot be obtained by merely reducing the mass flow rate, for obvious economic reasons. The alternative is to maximize the effective heat transfer surface to permit commercially acceptable flows and thermal production rates per wellpair. The key economic issues can be summarized as the total cost required to drill into a region of hot rock, and then to 
create sufficient reservoir area and volume for a commercial system.

Early economic modeling of HDR prototype systems considered the interaction between these key economic factors in trying to establish minimum performance goals for reservoir development [see Ch. 14 in Armstead and Tester (1987) for details]. These studies used prevailing costs for drilling and completing wells and for surface power plant facilities, and other prevailing economic factors. Break-even conditions were then estimated and sensitivity analyses carried out to quantify the importance of the various technical and economic factors.

With reasonable assumptions regarding resource quality and reservoir performance, the economic picture looks good; that is to say - if HDR reservoirs are created in areas with above-average thermal gradients and if they have productivities comparable with natural geothermal systems already in operation around the world - estimated costs for generating electricity are competitive. Whether HDR can compete more universally has yet to be demonstrated.

As expected, these early economic forecasts, carried out by various groups at Los Alamos (Cummings and Morris, 1979; Tester et al., 1979; Murphy et al., 1982), showed that break-even electricity prices are strongly dependent on drilling costs, debt interest rates, and anticipated rates of return on equity capital. The base-case condition assumed a $40^{\circ}$ to $60^{\circ} \mathrm{C} / \mathrm{km}$ resource, a reservoir productivity of $75 \mathrm{~kg} / \mathrm{s}$ per pair of wells with about $20 \%$ drawdown in 10 years, drilling costs about 2-1/2 times those of oil and gas wells of comparable depth, and real interest and equity rates of $9 \%$ and $12 \%$. The resulting break-even price was $5 \notin$ to $7 \notin$ per kilowatt-hour of electricity generated (in 1986 dollars).

An industrial group headed by Bechtel National, Inc., completed an independent study of HDR economics in 1987. The Bechtel (1987) study considered the development of an HDR system for generating elec- tricity in a high-grade $\left(-78^{\circ} \mathrm{C} / \mathrm{km}\right)$ resource located at the Roosevelt Hot Springs site in central Utah. After a careful review of the state of the art in HDR technology, the company developed a design for both the underground reservoir and the surface power plant to produce about $50 \mathrm{MWe}$, at a total capital cost of about $\$ 52.6$ million for the well/reservoir system and $\$ 68.9$ million for the power plant. When operating and maintenance costs were added, a levelized revenue requirement of $5.0 \notin$ per kilowatt-hour resulted, remarkably close to costs predicted by Armstead and Tester (1987) and the Los Alamos groups cited earlier.

Interested parties should review these studies as well as updated forecasts from the USDOE and the Electric Power Research Institute (EPRI) as they become available. For example, preliminary predictions from EPRI (Roberts, 1986) and from a 1986 UK study (Shock, 1986) show that HDR-produced heat and electricity are competitive with oil priced at about $\$ 14 /$ barrel for heat and $\$ 24 /$ barrel for electricity. This corresponds to an estimated price (in 1986 US dollars) of $\$ 2.50$ per million Btu for delivered heat or about 6.1 per kilowatt-hour for electricity. Again, these estimates agree quite well with earlier projections.

\section{ACKNOWLEDGMENTS}

This study was performed under the auspices of the US Department of Energy, in cooperation with the Energy Laboratory of the Massachusetts Institute of Technology. Portions of this report were presented at the 2nd North American Conference on Preparing for Climate Change, sponsored by The Climate Institute, Washington, DC (December 1988). We would also like to acknowledge the very thoughtful reviews of this manuscript provided by C. W. Myers and J. N. Albright. The editorial assistance of Harriett Allen is also gratefully appreciated. 
A New Energy Agenda for the 21st Century

\section{APPENDIX A}

\section{HDR RESOURCE - ITS MAGNITUDE AND DISTRIBUTION IN THE US}

A major incentive to meeting the technical challenges cited in Section III above is provided by the large magnitude and widespread distribution of the Hot Dry Rock resource throughout the US. Many estimates of the HDR resource base have been developed in the past 15 years. These estimates have been provided in US Geological Survey Circulars 726 and 790 (White and Williams, 1975; Muffler, 1979), by the Los Alamos National Laboratory [Hot Dry Rock Assessment Panel (HDRAP), 1977; Rowley, 1982], and by others (NRC, 1987; Armstead and Tester, 1987). Although the actual numerical estimates differ, their underlying methodologies are similar. Basically, an average geothermal temperature gradient, or an actual distribution of gradients across the US land mass, is integrated from the surface to an assumed accessible depth, to estimate the total thermal energy contained in the rock relative to some specified lower use temperature, like $85^{\circ} \mathrm{C}$. Then an initial minimum rock temperature is used to define the shallow boundary of the resource, while the rock temperature at an assumed maximum drilling depth defines the deeper, lower boundary. The HDR resource can then be estimated by using a gradient of $25^{\circ} \mathrm{C} / \mathrm{km}$ as a reasonable average for the US in rock having an average volumetric heat capacity of $2.2 \times 10^{15} \mathrm{~J} / \mathrm{km}^{3} \cdot{ }^{\circ} \mathrm{C}$. If we assume $150^{\circ} \mathrm{C}$ for the minimum initial rock temperature and $10 \mathrm{~km}(33,000 \mathrm{ft})$ for a maximum drilling depth, the total HDR resource base for the $9.36 \times 10^{6}$ $\mathrm{km}^{2}\left(3.61 \times 10^{6} \mathrm{sq}\right.$. miles) of the US land area is about 10 million quads, which is equivalent to about 1800 trillion barrels of oil or about 170,000 Prudhoe Bays. With the current US rate of energy consumption approaching 80 quads/year, this estimated HDR resource base could conceivably supply the country's needs for many thousands of years.

Estimates of the higher-grade HDR resource base have also been made. For example, recent studies suggest that more than $2 \%$, or about $1.8 \times 10^{5} \mathrm{~km}^{2}(6.9 \times$ $10^{4}$ sq. miles) of the US land area, should have average gradients in excess of $45^{\circ} \mathrm{C} / \mathrm{km}$ (Kron and Heiken, 1980). If we follow the same approach used for the lower-grade HDR resource, the higher-grade resource would amount to some 650,000 quads, which is equivalent to 118 trillion barrels of oil. Figure 2 provides estimates of the geothermal gradient distribution across the US.

However, these high- and low-grade HDR resource estimates are clearly upper limits since it remains to be shown just how much of this vast resource base can be recovered within existing technical and economic constraints. As a point of comparison, usually less than half of the oil in an underground reservoir is actually produced. At this stage of its development, it is not known what fraction of the HDR resource base is recoverable. However, even if only $0.1 \%$ or $0.01 \%$ of the accessible HDR resource base is ultimately extracted, the impact on the US energy supply would be far-reaching.

In previous forecasts of HDR-generated electricity, high-grade HDR resources would be developed first for practical economic reasons, as these resources will require much shallower drilling depths and consequently will result in significantly lower reservoir development costs. For example, for a $60^{\circ} \mathrm{C} / \mathrm{km}$ resource, one needs to drill only to depths of $4 \mathrm{~km}(13,000 \mathrm{ft})$ to reach initial rock temperatures of about $250^{\circ} \mathrm{C}$, which is more than sufficient for generating electricity. For a $30^{\circ} \mathrm{C} / \mathrm{km}$ resource, however, the depth to reach the same temperature level would approximately double, which could result in as much as a sevenfold increase in drilling costs (Armstead and Tester, 1987). If HDR is used as part of an integrated energy conversion system, lower-grade HDR resources can be economically utilized, even in the generation of electricity (see Section IV).

In terms of resource size, HDR compares with other nonfossil resources often proposed as solutions to our long-term national energy supply problem, most notably controlled thermonuclear fusion and solar photovoltaics. Unfortunately, HDR is often mistakenly regarded as just another localized geothermal resource available primarily in the western states. 


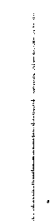




\section{APPENDIX B}

\section{CURRENT STATUS OF DEVELOPMENT: REVIEW OF FIELD PROGRAMS}

Through 1986, only two major field programs in the world were developing HDR technology: the US program at the Fenton Hill site in northern New Mexico and the UK program at the Rosemanowes site in Cornwall in southwest England. Los Alamos National Laboratory has managed the US program for the USDOE (and its predecessor agencies) since its beginnings in the early 1970s. The Camborne School of Mines manages the UK program, which began in the field in 1979 and is primarily under UK DOE sponsorship (see Bachelor, 1984). Recently, however, Japan, Russia, France, and Germany have begun significant HDR development programs.

In 1979, an International Energy Agency agreement provided for non-US participation in the USDOE HDR program at Fenton Hill. Under that agreement, Kernforschungsanlage-Julich Gmbh (representing the Federal Republic of Germany) and the New Energy Development Organization (representing the Government of Japan) participated in the project from 1980 to 1986. They provided $\$ 32.5$ million in supporting funds and assigned a number of technical personnel to work at the Los Alamos National Laboratory. The Los Alamos team (Smith, et al., 1975; Dash et al., 1983; and Whetten et al., 1986) has documented progress at Fenton Hill in detail, so we will only summarize results here.

The world's first HDR reservoir was completed at Fenton Hill in 1977 at a depth of about $2.6 \mathrm{~km}(8500$ $\mathrm{ft}$ ), with rock temperatures of $185^{\circ} \mathrm{C}$. This so-called Phase I system was enlarged in 1979 by additional hydraulic stimulation and was operated successfully for about 1 year to test the feasibility of the heat extraction concept and to measure the thermal and hydraulic performance of the reservoir. Overall, the results of the Phase I testing were very positive, clearly demonstrating that heat could be extracted at reasonable rates from a hydraulically stimulated region of low-permeability hot crystalline rock without serious technical or environmental problems. Although the reservoir was too small for commercial use, it provided an excellent testbed for verifying reservoir models designed to simu- late thermal performance, and for developing techniques and equipment to characterize reservoir geometry.

To extend HDR technology to the higher temperatures and heat production rates required to support a commercial-sized electric generating plant, the development of a larger and hotter HDR reservoir was initiated at Fenton Hill in late 1979. This reservoir is often referred to as the Phase II reservoir.

The Phase II system was designed to have two inclined wellbores with a vertical separation of approximately $300 \mathrm{~m}$. The bottom $1000 \mathrm{~m}$ of each hole was directionally drilled at an inclination $35^{\circ}$ from the vertical and in a horizontal direction parallel to the least principal stress direction as measured in the shallower Phase I system. The upper well EE-3, intended for production, was positioned above the injection well EE-2. Early attempts to connect EE-2 and EE-3 using hydraulic fracturing techniques were unsuccessful despite the substantial volumes of water injected during massive fracturing operations in 1982 to 1983 . The last major attempt occurred in December 1983, when almost $21,500 \mathrm{~m}^{3}$ of water was injected at a depth of approximately $3500 \mathrm{~m}$ in EE-2, at surface pressures up to $48 \mathrm{MPa}(7000 \mathrm{psi})$, and at an average injection rate of $108 \mathrm{~kg} / \mathrm{s}$. Analyses of the microseismic events induced by water injection during this test showed that the stimulated zone was three dimensional rather than linear, with dimensions approximately $800 \mathrm{~m}$ high by $900 \mathrm{~m}$ wide in the north-south direction by $200 \mathrm{~m}$ thick in the east-west direction. Unfortunately, this zone did not intersect the upper EE-3 well as originally predicted but instead inclined to the east at about the same angle as the directionally drilled boreholes. This seismically active volume is equivalent to 150 million cubic meters of stimulated rock, which is about 6800 times greater than the actual volume of injected water. Subsequent analyses by the Los Alamos team indicated that the microseismically active region represents the stimulation of multiple natural joints rather than a single vertical fracture and that a shear-slippage mechanism was dominant in the microseismic signals. This finding agrees with results from Rosemanowes, but it is 
inconsistent with conventional tensile failure theories originally thought to be operative.

With no hydraulic connection to the upper well, the Los Alamos team decided to sidetrack and redrill EE-3 to create a workable rescrvoir. The microseismic event map from the $21,500 \mathrm{~m}^{3}$ injection test was used to design the EE-3A trajectory for maximum penetration through the seismic event cloud. The first major flow connections to EE- 2 were obtained by fracturing from EE-3A through a tubing string connected to a high-temperature openhole packer set at $3520 \mathrm{~m}$. Additional stimulations were attempted lower in EE-3A using openhole packers, with some success. The final result was a well-connected HDR reservoir ready to be tested.

In March and April of 1986, the new Phase II reservoir was prepared for initial hydraulic circulation and heat extraction testing. A steel liner was cemented in EE-3A to isolate the deep injection interval; the surface piping system was finished; and the air-cooled heat exchangers used throughout the Phase I tests were connected. A 30-day flow test, referred to as the Initial Closed-Loop Flow Test, was started on 19 May 1986 and was completed on 18 June 1986 (Dash et al., 1989). Table B-I compares initial reservoir parameters for this Phase II system to those for earlier Fenton Hill and Rosemanowes reservoirs.

Measured tracer-determined residence-time distributions highlight the differences in flow patterns between the Phase I and II systems at Fenton Hill. A larger reservoir (modal) volume, with a larger portion of the flow distributed in longer residence-time flow paths, was found for the Phase II system. During the 30-day test, the modal volume increased from 270 to $350 \mathrm{~m}^{3}$, while the flow impedance decreased from about 4.5 to $2.1 \mathrm{GPa} \cdot \mathrm{s} / \mathrm{m}^{3}$, which is comparable with that observed in the enlarged Phase I system and in the Phase II system at Rosemanowes. With a constant reinjection temperature of $20^{\circ} \mathrm{C}$, the production temperature steadily increased to about $190^{\circ} \mathrm{C}$, corresponding to a thermal power level of about $10 \mathrm{MW}$. No thermal drawdown was observed. Furthermore, silica and Na-KCa geothermometers indicated in situ reservoir temperatures of about $242^{\circ}$ and $222^{\circ} \mathrm{C}$, respectively. These temperatures are consistent with an initial measured rock temperature of $232^{\circ} \mathrm{C}$ at an average reservoir depth of $3550 \mathrm{~m}$. Temperature surveys of the production/ injection region indicate a multiply jointed network of fractures connecting EE-2 and EE-3A. Water loss rates of $2.3 \mathrm{l} / \mathrm{s}$ (about $19 \%$ of the injected flow rate) were observed after only 15 days of flow testing, but this phase of the test was too short to extrapolate to steadystate values, which undoubtedly would have been much lower.

Los Alamos plans to continue testing the redrilled Phase II system at Fenton Hill with a long-term (at least 1-year) circulation test currently scheduled for 1990. The objectives are to characterize steady-state power production, flow impedance, and water loss by monitoring injection and production flow rates and temperatures, and to infer the state of reservoir thermal drawdown by using chemically reactive tracers. 
TABLE B-I. COMPARISON OF HDR RESERVOIR CHARACTERISTICS

(updated from Armstead and Tester, 1987)

\begin{tabular}{lll}
\multicolumn{2}{c}{ Fenton Hill } & (US) \\
\hline Original & Enlarged & Redrilled \\
Phase I & Phase I & Phase II
\end{tabular}

\section{Rosemanowes (UK)}

Original Redrilled

Phase I Phase II Phase II

$\begin{array}{lllllll}\text { Average reservoir } & 2,700 & 2,840 & 3,550 & 100 & 2,100 & 2,100\end{array}$

depth ( $m$ )

Average initial

rock temperature $\left({ }^{\circ} \mathrm{C}\right)$

185

190

232

15

80

80

Average wellbore

100

$300 \quad 150-300$

40

300

200-300

separation (m)

Modal reservoir

volume $\left(\mathrm{m}^{3}\right)$

$11-27 \quad 136-187 \quad 270-350$

50

$2,500-3,600$

153-780

Production flow

7-16

6-8

12-14

1-10

6-10

$12-24$

rates $(\mathrm{kg} / \mathrm{s})$

Cumulative operating pcriod (h)

Terminal flow impedance $\left(\mathrm{GPa} \cdot \mathrm{s} / \mathrm{m}^{3}\right)$

Range of water loss as \% of injection rate

2,500

7,320

744

1,000

5,000

$24,000^{\mathrm{a}}$

$0.33^{c}$

1.56

2.1

0.03

1.6

0.60

7-1\%

$15-10 \%$

$35-19 \%^{d}$

$1-5 \%$

$40-60 \%$

$25-15 \%^{b}$

Nominal thermal power output (MW)

310

$<1$

1

$1-4$

10

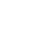

${ }^{a}$ As of 30 September 1988.

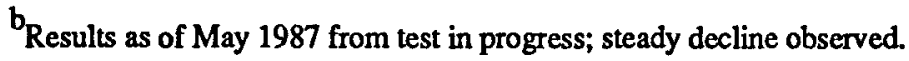

Measured impedance at end of low back pressure portions of test (buoyancy corrected).

${ }_{19 \%}$ after only 15 days of circulation at $27 \mathrm{MPa} ; 35 \%$ after an additional 15 days at a higher 31-MPa injection pressure (associated with significant reservoir growth). 



\section{APPENDIX C \\ REQUIREMENTS FOR ESTABLISHING HDR FEASIBILITY}

\section{ACCOMPLISHMENTS TO DATE}

Many of the critical questions regarding the development of HDR geothermal energy have already been answered. We have adequately demonstrated that one can drill into regions of hard crystalline rock at temperatures above $300^{\circ} \mathrm{C}$, can then create large underground reservoirs by hydraulic stimulation and fracturing, and can mine heat for extended periods without dire practical or environmental consequences. We have not seen the failure of any hypothesis involving basic physical principles regarding the effectiveness of the heat-mining process. Nature has, in fact, provided a few unexpected surprises that have enhanced reservoir development. The self-propping of natural joints by a sheardisplacement mechanism during the injection of pressurized fluid has resulted in acceptable reservoir flow impedances, without the need for artificial proppants or chemical treatment. Further, we have found that the hydraulic stimulation of a region of naturally jointed crystalline rock can lead to a dilated volumetric core of favorably orientated and interconnected joints. These volumetric systems will undoubtedly result in improved heat extraction rates over the idealized parallel set of discrete vertical tensile fractures that was originally envisioned. Finally, the hydraulic stimulation of naturally jointed crystalline rock is usually accompanied by harmless acoustic emissions that can be located with great precision using standard seismic techniques. Therefore, HDR reservoirs can be located and defined to a degree unprecedented in other areas of subsurface geophysical exploration. Key program accomplishments are summarized in Table C-I.

\section{REMAINING TASKS AND FEASI- BILITY ISSUES}

The main technical task remaining involves the enlargement of the two-well HDR reservoir concept to meet commercial power production requirements. Although this is by no means a trivial task, as field efforts at Fenton Hill and Rosemanowes have demonstrated, it requires only the logical extension of established oil and gas reservoir development technology. Therefore, HDR development does not require the technical "quantum jumps" that will be necessary before other new power technologies become commercial. In this context, the HDR heat-mining concept is amenable to physical extension, either vertically or laterally. If success can be achieved with a single pair of wells and an interconnecting network of fractures, then this doublet system can be treated as a modular unit for scaleup, to extract heat from much larger adjacent volumes of hot rock. The Phase I reservoir at Fenton Hill has, in fact, served as a module for the design of the Phase II multiply fractured system. If reservoir stimulation can be achieved as systematically as envisioned, then this last technical hurdle of creating and testing a commercial-sized system at Fenton Hill is well within reach during the next 5 years. However, even if the operation of the Phase II System at Fenton Hill is completely successful, several major issues still must be resolved to reduce the real and perceived risks and costs of developing commercial HDR ventures at other sites. These issues deal primarily with the continued engineering of the underground system and include:

- Drilling and Completion - Improved conventional and directional hard-rock drilling techniques that lead to increased penetration rates and reduced costs will encourage commercial HDR development. Further, new or improved methods of wellbore completion and reservoir isolation are needed that circumvent most of the problems associated with conventional cemented-in liner and/or casing completions - particularly for multiple HDR reservoir regions created from the same wellbore. Such methods are necessary because the formulation and placing of cements is very difficult at temperatures approaching $300^{\circ} \mathrm{C}$ and depths up to $5 \mathrm{~km}$.

- Reservoir Stimulation - Improved techniques are needed for multiple hydraulic stimulations in low-permeability geologic environments 


\section{TABLE C-I. MAJOR ACCOMPLISHMENTS OF THE US HOT DRY ROCK} GEOTHERMAL DEVELOPMENT PROGRAM

1. The initial assessment of the US HDR resource is complete, and other highgrade sites have been identified for development.

2. Multiple demonstrations have shown that wells can be directionally drilled and completed to depths up to $5 \mathrm{~km}$ in hard crystalline rock at temperatures above $300^{\circ} \mathrm{C}$.

3. HDR reservoirs have been created using hydraulic pressurization to stimulate (i.e., open and dilate) multiple natural-joint networks over wellbore separation distances of $300 \mathrm{~m}$ or more, and with acceptable flow impedances, in two different systems (Phase I at $2.6 \mathrm{~km}$ and Phase II at $3.6 \mathrm{~km}$ ).

4. Extensive flow testing has been carried out at Fenton Hill to verify the viability of the HDR heat-mining concept in hot rock of low initial permeability.

5. Diagnostic techniques and equipment for a variety of in situ geophysical measurements up to $300^{\circ} \mathrm{C}$ have been developed.

6. Passive and active microseismic methods have been developed for mapping hydraulically stimulated regions.

7. Inert and reactive tracer techniques have been developed for sizing reservoirs and characterizing flow patterns.

8. Thermal-hydraulic models for simulating the performance of multiply fractured HDR reservoirs have been developed and verified.

to yield multiply connected injection and production wells, with large enough swept heat transfer areas and volumes to support commercial heat production rates for 10 to 30 years. Improved geophysical diagnostic techniques are required to measure in situ stress states and to better understand how natural and artificial fracture systems propagate and dilate under fluid pressurization. For example, microseismic event maps need to be still more quantitatively related to active reservoir volumes.

- Long-Term Reservoir Performance - A commercial-scale HDR reservoir nceds to be operated at least 1 to 2 years to demonstrate its thermal-hydraulic performance and to verify models being developed to predict reservoir performance. Because of severely reduced funding, only limited testing of the Phase II reservoir at Fenton Hill has been accomplished to date (May 1989). Although the results of this flow testing have been positive, it is too early to predict long-term reservoir performance in terms of the rates of thermal drawdown and water loss, impedance changes, induced seismicity, and geochemical behavior. Furthermore, the measured growth in reservoir flow volume - in a nonextending reservoir region needs to be better characterized, particularly with respect to how it may influence thermal drawdown rates and flow impedance.

Work at Los Alamos is currently addressing all of these items, and at this time we can report considerable progress toward reducing the costs associated with drilling and completion and with reservoir stimulation. Recent deep hard-rock drilling experience at Fenton Hill has shown that HDR drilling costs can be significantly less than equivalent hydrothermal drilling costs and much closer to conventional oil and gas drilling costs. 
In the early $1980 \mathrm{~s}$, the Los Alamos National Laboratory directionally drilled two deep holes (EE-2 and EE-3) at Fenton Hill at average completed costs in excess of $\$ 16$ million in 1988 dollars $(\$ 3550 / \mathrm{m}$ or $\$ 1080 / \mathrm{ft})$. However, inexperience in drilling highly deviated holes in this high-temperature hard-rock environment greatly added to the costs of these two holes (see Fig. 5). More recently (1985 to 1987), the Laboratory has redrilled the deeper, hotter portions of both these holes (EE-2A and EE-3A) at a significantly lower cost/meter, as a result of improved drilling efficiency.

One of the most significant factors in reducing drilling costs - in combination with more experience - has been the elimination of most of the directional drilling. Analysis of the structure of the Phase II reservoir (Fehler et al., 1987) and a reanalysis of the upper Phase I reservoir have indicated that significant amounts of directional drilling normally may not be required to create and access HDR reservoirs. Typically, one or more of the naturally occurring joint sets will be somewhat inclined from vertical. Further, most deep boreholes end up being naturally inclined $10^{\circ}$ to $20^{\circ}$ from the vertical - without any overt directional drilling procedures. The combination of these two inclination factors should allow the initial drilling, reservoir development, and then the drilling of the second access borehole to be done with a minimum of directional drilling.

In both of the more recent redrilling programs at Fenton Hill, two other significant changes were made in the drilling strategy:

- High-temperature clay-based drilling fluids were used, instead of just water, to remove cuttings and for lubrication.

- Comprehensive inspections of the drill pipe and drilling assemblies were scheduled, and the drill pipe was rotated on a routine basis.

These two drilling procedure changes completely eliminated pipe twist-offs and most stuck drilling assembly problems that plagued earlier drilling programs at Fenton Hill (Armstead and Tester, 1987).

Based on $1310 \mathrm{~m}$ (4300 ft) of straight-hole (nondirectional) drilling during the most recent Fenton Hill redrilling programs in EE-3A and EE-2A, over depths from 2900 to $4000 \mathrm{~m}(9,500$ to $13,200 \mathrm{ft})$, the overall average drilling cost was $\$ 500 / \mathrm{m}(\$ 152 / \mathrm{ft})$. For comparison, the associated $350 \mathrm{~m}(1,150 \mathrm{ft})$ of directional (downhole motor) drilling averaged $\$ 775 / \mathrm{m}$ (\$236/ft).

Completion costs for EE-2A, including a cemented-in liner and a full tieback string of 7-in (178$\mathrm{mm}$ ) casing to the surface, were $\$ 840,000$. These completion costs should be quite representative of the anticipated completion costs for a typical HDR well to a depth of about $3.5 \mathrm{~km}$.

Extrapolating the most recent Fenton Hill experience with EE-2A to an HDR reservoir depth of $4.5 \mathrm{~km}(15,000 \mathrm{ft})$, the total reservoir development costs are estimated to be (1988 dollars)

\begin{tabular}{|lc|}
\hline & \$ million \\
\hline $\begin{array}{l}\text { Nondirectional drilling costs, two wells } \\
\text { at } \$ 500 / \mathrm{m}(\$ 152 / \mathrm{ft})\end{array}$ & 4.56 \\
$\begin{array}{l}\text { Additional cost for directional drilling } \\
\text { Reservoir development costs }\end{array}$ & 0.10 \\
Wellbore completion costs, two holes & 2.32 \\
Drilling rig mobilization costs (twice) & 0.50 \\
Logging and preliminary testing costs & 0.22 \\
Contingency (25\%) & $\underline{2.08}$ \\
Total cost for on e w ellp air & $\mathbf{1 0 . 3 8}$ \\
\hline
\end{tabular}

For comparison purposes, these extrapolated drilling costs of $\$ 5.19$ million per well have been plotted on Fig. 5 to show the improvement over earlier experience at Fenton Hill, which on the same basis corresponds to about $\$ 16$ million per well. Note that the estimated costs for a 4.5-km HDR well approach those for an oil or gas well to the same depth. Some drilling engineers would argue that deeper HDR wells could be even less expensive than comparable oil and gas wells because HDR holes are stable and therefore would require less costly casing and drilling fluid programs.

Although much progress has been made with microseismic and other mapping techniques, several critical reservoir development issues remain to be resolved. Primarily, we need improved techniques to 
measure the earth stresses in the reservoir region and to better define the structure of the stimulated joints. In this regard, a new wellbore technique for measuring both the directions and the relative magnitudes of the two principal horizontal earth stresses is the subject of a Los Alamos National Laboratory study, and improved methods of seismic reservoir delineation are being researched at Los Alamos and the Camborne School of Mines.

However, the microseismic techniques mentioned previously measure only a part of the pressure-stimulated joint structure within the reservoir, that is, the orientation of those joints that have experienced significant shear displacement. Unfortunately, other pressure-dilated features within the reservoir region, which are oriented subparallel to the principal stress directions, will be essentially aseismic, even though they may represent major flow paths (Brown, 1988). A promising technique now available for mapping the joint structure in an HDR reservoir (both before and after stimulation) is the high-temperature, high-resolution, borehole acoustic televiewer (BAT) presently under active development at Los Alamos.

Fluid pressures and the injection rates required to open and propagate fractures at depth within the hot zone of low-permeability rock determine reservoir stimulation costs. Early stimulation tests at Fenton Hill have established the framework for bracketing costs associated with fracturing operations, and recent tests have furthered our ability to estimate costs. For example, most of the Phase II reservoir at Fenton Hill was created during one extensive stimulation operation in December 1983. For 61 hours, fluid was injected at an average rate of $108 \mathrm{l} / \mathrm{s}(40 \mathrm{bpm})$ and a pumping pressure of $48 \mathrm{MPa}$ (7000 psi), for a cumulative injected volume of almost $21,500 \mathrm{~m}^{3}$ (5.7 million gallons). The total cost for creating this reservoir was about $\$ 800,000$, at an injection pressure level near the upper bound for anticipated HDR reservoir stimulation pressures (a significant cost factor). If this massive stimulation were to be repeated with what we now know - at lower pumping rates, with larger-diameter injection pipe, and without costly diverting agents or other unnecessary chemical additives - today's total cost for creating the Phase II reservoir would be closer to $\$ 600,000$. However, keep in mind that these stimulation costs are estimates, subject to wide variation from site to site. Typically, however, they will represent only a small portion (less than 10\% to 15\%) of the total reservoir development costs, with drilling and well completion costs dominating the economic picture. 


\section{APPENDIX D}

\section{POWER GENERATION OPERATING CHARACTERISTICS}

One of the axioms of power conversion is that the most efficient systems utilize the heat source - or sources - to transfer heat to the working fluid over a temperature range as close as possible to the source temperature. This introduces the concept of availability (or second law efficiency) into the design and selection process for power generation systems. Fossil fuels, as high-grade fuels, are best utilized by supplying heat to working fluids at high temperature. Conversely, geofluids - i.e., low-grade "fuels" — are more appropriate for supplying heat to working fluids at lower temperature.

As a consequence, the best utilization - in a thermodynamic sense - of the very large HDR resource would be low-temperature heating applications: for direct process or space heating, or feedwater heating in otherwise conventional fossil-fueled steam Rankinecycle power plants. As pointed out by Khalifa (1980), this statement holds for HDR geofluid production temperatures up to at least $250^{\circ} \mathrm{C}$. The corollary is that high-grade fossil fuels - and obviously electricity itself - are poorly utilized in a thermodynamic sense when they are used for low-temperature applications such as space and domestic hot water heating.

One further point needs to be made concerning electric power generation from HDR or other geothermal resources. The direct extraction of work from such low-grade geofluids normally requires the vaporization of a working fluid that can be efficiently expanded in a turbine. However, in a hybrid fossilgeothermal energy conversion system, the geofluid is confined to low-temperature preheating requirements, whereas the fossil fuel is confined to high-temperature requirements (vaporization, superheating, and reheating). As a consequence, in a hybrid power conversion system, the geothermal heat is converted to electricity at the overall hybrid plant efficiency ( $43 \%$ to $45 \%$ ), which is much higher (1.5 to 2 times) than that for a pure vapor, binary cycle geothermal plant.

With the widespread availability of the HDR resource, site-specific considerations are considerably reduced. The more important issues are the load center requirements and the availability of fossil fuels. One would envisage, in contrast to utilizing naturally occurring geofluid resources, that an HDR-based hybrid plant would first be sited on the basis of standard fossil-fueled power plant siting criteria. Then, the nearby region would be surveyed for the most appropriate HDR reservoir development site, and a compromise power plant site finally selected.

\section{HYBRID STEAM CYCLE WITH HDR GEOFLUID PREHEATING (Fig. D-1)}

The hybrid cycle concept (DiPippo et al., 1981; Khalifa, 1980) would be appropriate in many places where fossil-fueled electric power is now being generated. The main variable, depending on the geofluid temperature, is the number of regenerative feedwater heaters that would be replaced. From Khalifa's work (1980), for a state-of-the-art fossil-fueled steam power plant with seven stages of regenerative (turbine steam bleed) feedwater heating, the following results are obtained.

\begin{tabular}{|cc|}
\hline $\begin{array}{c}\text { Geofluid Production } \\
\text { Temperature } \\
\text { (C) }\end{array}$ & $\begin{array}{c}\text { Number of Feedwater } \\
\text { Heaters Replaced }\end{array}$ \\
\hline 250 & 7 (all) \\
200 & 5 \\
150 & 3 \\
\hline
\end{tabular}

A 500-MWe hybrid power plant utilizing an HDR resource with a production geofluid temperature of $200^{\circ} \mathrm{C}$ would consume about $10 \%$ less fossil fuel than an equivalent all-fossil power plant of the same capacity. Although a $10 \%$ fuel savings is not striking, when developed nationwide, such hybrid plants would represent a marked savings in fuel and all the attendant ramifications. For a hybrid power plant of this size, three HDR wellpairs typically would be needed to furnish the necessary feedwater heating, representing about $20 \%$ of the total energy consumed in the hybrid plant. 
Results from a study conducted for the City of Burbank (1977) suggest that, for a geofluid temperature of $200^{\circ} \mathrm{C}$, the hybrid power plant would offer from $7.5 \%$ to $10 \%$ savings in the cost of electric energy relative to the reference fossil-fueled power plant. The Burbank study further showed that, because of increased efficiency, the cost of a hybrid power plant (including geothermal wells) is not likely to be much different from that of a conventional fossil-fueled power plant of the same capacity.

\section{HDR-AUGMENTED COMBINED- CYCLE GAS TURBINE (Fig. D-2)}

The newest generation of gas turbine peaking units, such as GE's 136-MW unit (Brandt, 1987), has been designed with integrated, combined-cycle power generation in mind. With gas turbine exhaust temperatures in the range of $590^{\circ} \mathrm{C}$, the combined-cycle bottoming steam units are very similar in performance to state-of-the-art supercritical fossil-fueled steam Rankine power plants with an initial $540^{\circ} \mathrm{C}$ steam temperature, a single reheat cycle, seven feedwater heaters, and a thermal efficiency of $43 \%$ (DiPippo et al., 1981). In the combined-cycle configuration, these gas turbine units are capable of about 190-MWe output with overall thermal efficiencies approaching 47\% (Moore et al., 1988). Dwain Spencer of the Electric Power Research Institute (EPRI) anticipates that combustion turbines will account for $40 \%$ to $60 \%$ of all additions to the total US electric power generation capacity - about 40,000 to $60,000 \mathrm{MW}$ of new capacity - over the next 10 to 12 years (Spencer, 1988). Furthermore, many of these combined-cycle units are now in baseload service and have shown excellent reliability. In a direct analogy to the application of HDR heating to the previous hybrid steam cycle, the HDR geofluid would be used for feedwater preheating in the steam Rankine portion of the combined-cycle combustion turbine.

\section{HDR DIRECT HEAT USE (Fig. D-3)}

In many situations, the most appropriate and efficient use for HDR geothermal energy would be in lowtemperature direct heat applications, as a substitute for burning fossil fuels. It is here that HDR can effect the most significant reductions in $\mathrm{CO}_{2}$ emissions with no economic penalty. Using the commercially mature drilling costs shown in Fig. 4, the development of a two-well HDR reservoir at moderate temperature $\left(\sim 140^{\circ}\right.$ to $\left.170^{\circ} \mathrm{C}\right)$ in the eastern US would cost about $\$ 12.5$ million including surface pumping equipment and heat exchangers. For a geofluid production rate of $63 \mathrm{~kg} / \mathrm{s}(1000 \mathrm{gpm})$ at $150^{\circ} \mathrm{C}$, heat could be supplied for about $\$ 2.40$ per million $B t u$, which is equivalent to a natural gas cost of $\$ 2.40$ per 1000 SCF - competitive at today's prices.

\section{HDR BASELOAD ELECTRIC POWER GENERATION (Fig. D-4)}

As discussed earlier in this section, given the choice, the better power generation use for the low-grade HDR resource would be for feedwater preheating in hybrid power plants. However, for specific end-use requirements such as cogeneration or limited electrical loads, a small "pure" geothermal Rankine power plant may be more appropriate. Depending on the available resource temperature and the utility involved, these Rankine-cycle power plants could be of a multiflash steam or binary cycle configuration (Tester, 1982; Khalifa, 1980).

\section{HDR-AUGMENTED LIQUID PUMPED STORAGE (HDRALPS) (Fig. D-5)}

Of the five HDR utilization concepts discussed in this report, HDRALPS is perhaps the most interesting and innovative. In this concept, excess baseload capacity is used to inflate the HDR reservoir during off-peak hours. As the fractured and interconnected reservoir region is dilated, the surrounding rock is elastically compressed. In the HDR example, only a small percentage increase in the pre-existing state of reservoir inflation would be accomplished during any given period of pressurization - about $5 \%$ to $10 \%$.

Then, during the next period of peak power demand, geofluid would be produced from the reservoir through another wellbore, returning a portion of the stored fluid (again 5\% to 10\%) at high pressure and high temperature. In other applications, the geofluid could be produced continuously if desired. 


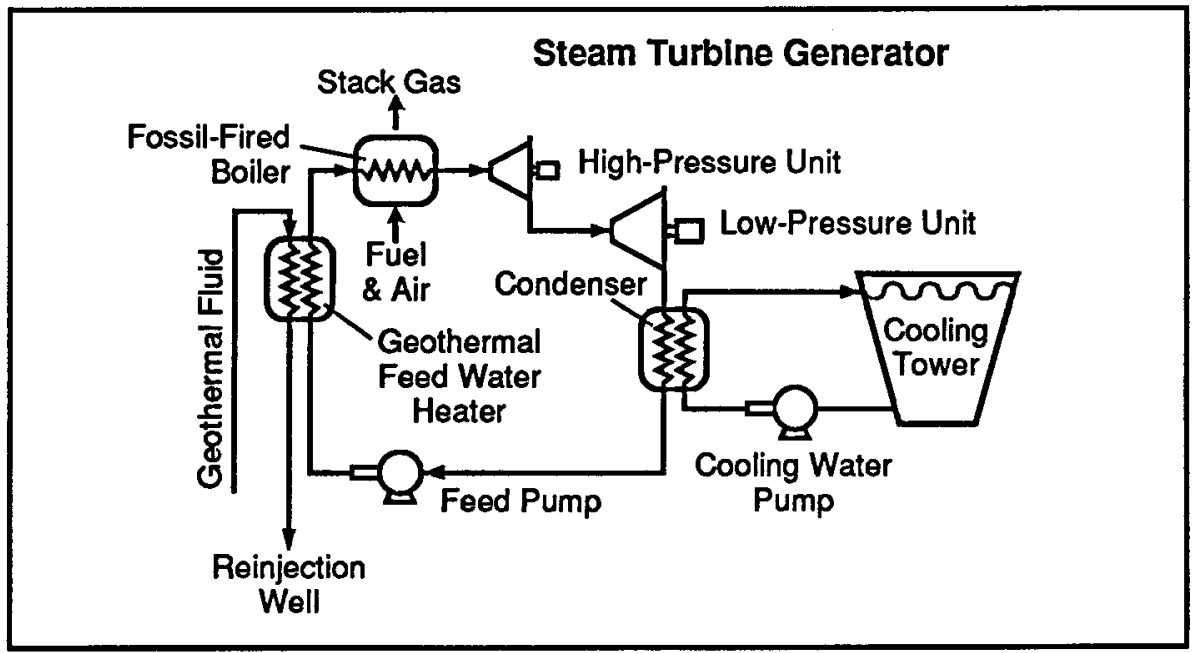

Fig. D-1. Hybrid steam power cycle with a fossilfired boiler and HDR preheater.

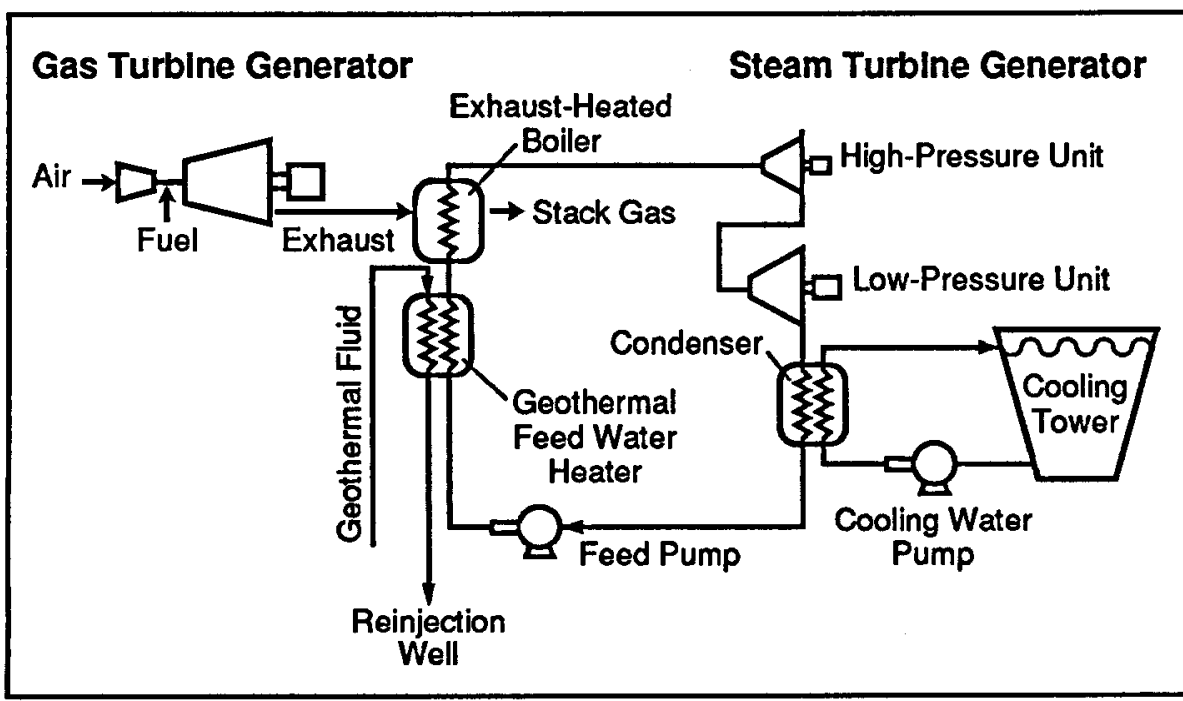

Fig. D-2. HDR-augmented combined-cycle gas turbine.

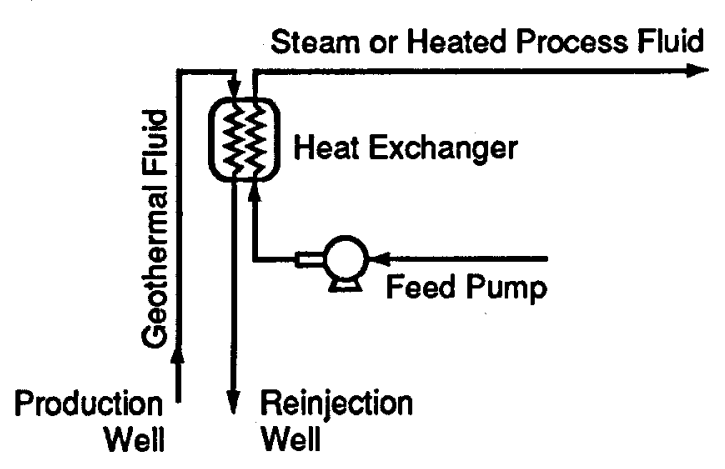

Fig. D-3. HDR direct heat use. 


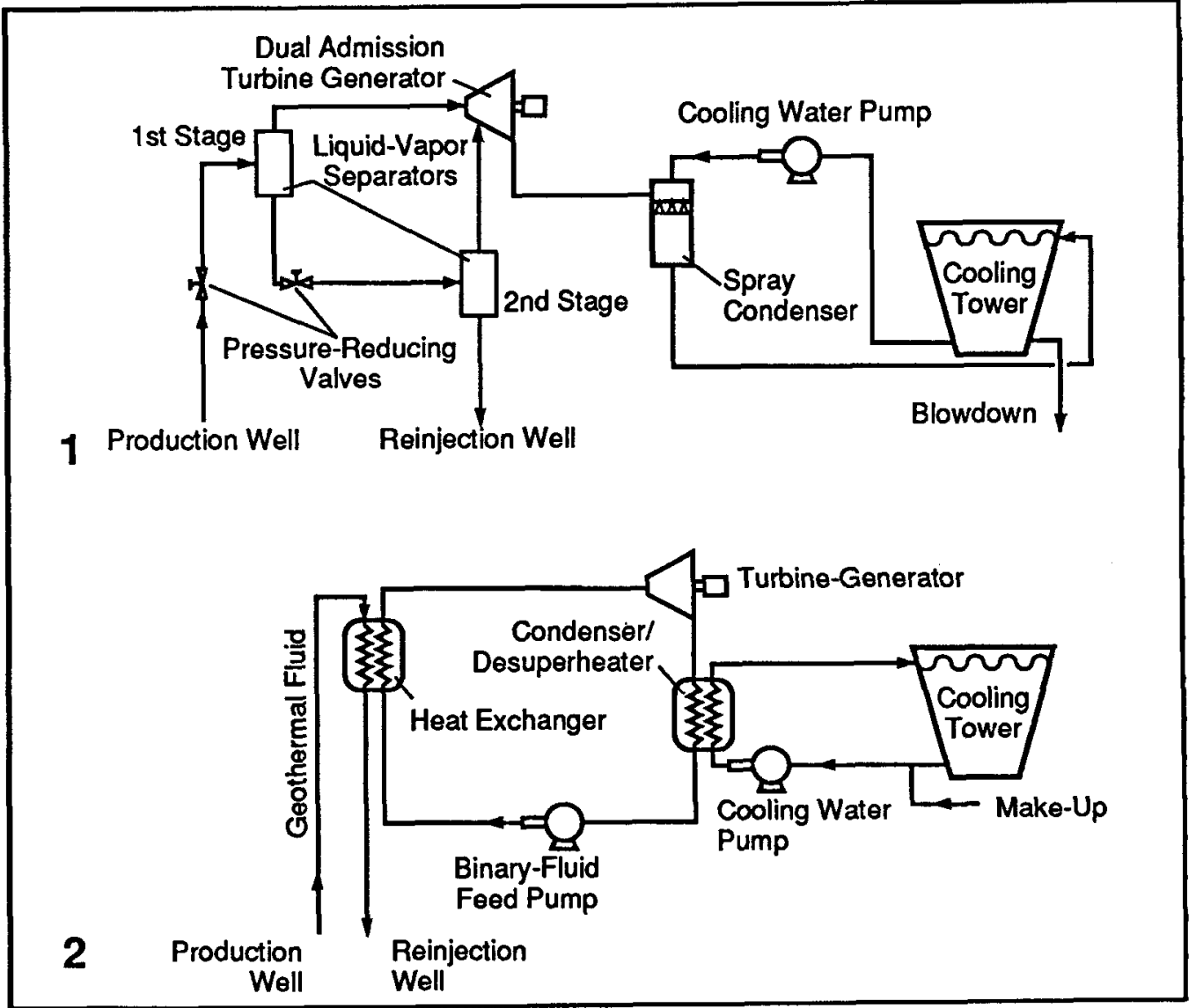

Fig. D-4. Electric power cycle configurations for use with an HDR system using pressurized water to extract heat. (1) Two-stage flashing cycle. (2) Binary-fluid Rankine cycle. (Armstead and Tester, 1987)

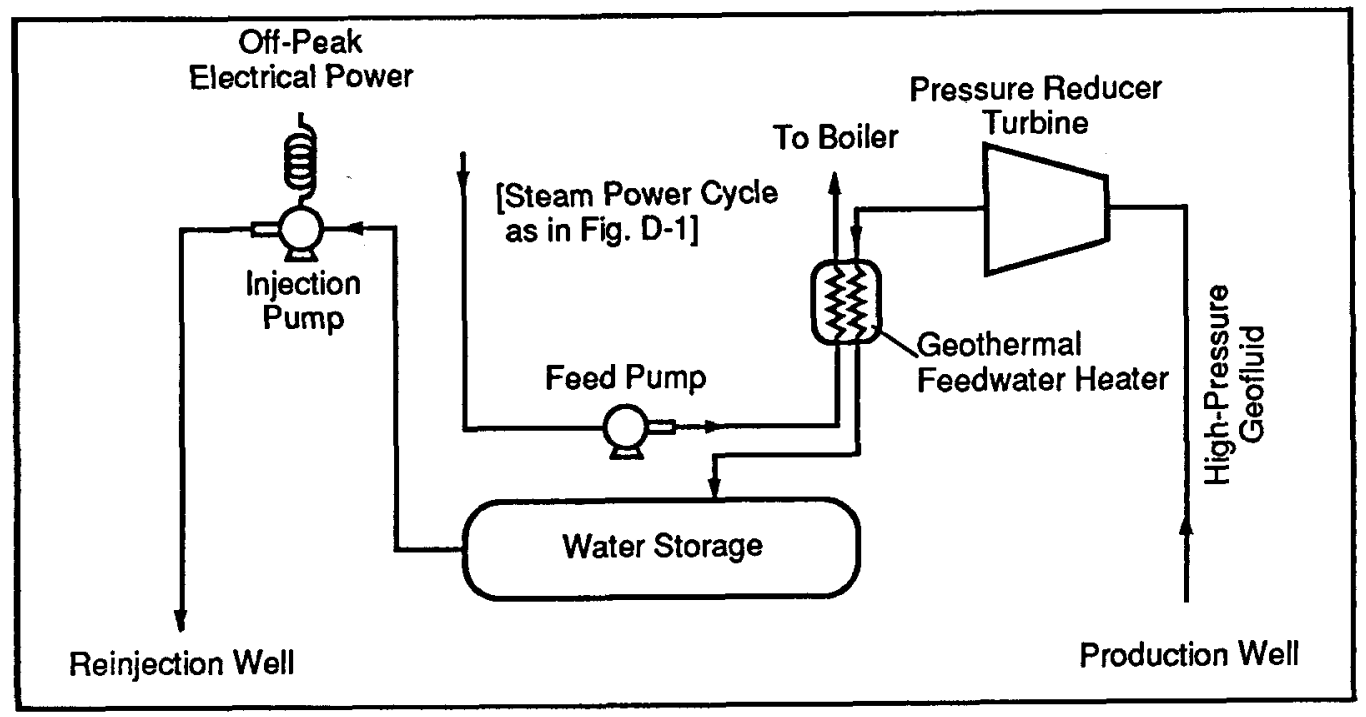

Fig. D-5. HDRALPS: HDR-augmented liquid pumped storage. 


\section{REFERENCES}

Armstead, H.C.H., Geothermal Energy, 2nd ed. (E.F. Spon, London, 1983).

Armstead, H.C.H., and J.W. Tester, Heat Mining (E.F. Spon, London, 1987).

Batchelor, A.S., "Hot Dry Rock Geothermal Exploitation in the United Kingdom," Mod. Geol.9, 1-41 (1984).

Bechtel National, Inc., "Hot Dry Rock Venture Risks Investigation," Final report for the USDOE, under contract HDE-AC03-86SF16385, San Francisco, California (1987).

Brandt, D.E., "Heavy-Duty Turbopower: The MS7001F," Mech. Eng. 109 (7), 28-36 (1987).

Brown, D.W., "The Potential for Large Errors in the Inferred Minimum Earth Stress When Using Incomplete Hydraulic Fracturing Results," Int.J. Rock Mech. Min. Sci. (1989).

Brown, L.R., A. Durning, C. Flavin, L. Heise, J. Jacobson, S. Postel, M. Renner, S. Pollock-Shea, and L. Starke, State of the World, 1988: A Worldwatch Institute Report on Progress Toward a Sustainable Society (W.W. Norton \& Co., New York, 1988).

Chandler, W.U., H.S. Geller, and M.R. Ledbetter, Energy Efficiency: A New Agenda, American Council for an Energy-Efficient Economy, Washington, DC (1988).

City of Burbank, "Site-Specific Analysis of Hybrid Geotherma1/Fossil Power Plants," prepared for ERDA/DGE, Contract E(0-4-1311), Public Service Dept., Burbank, California (June 1977).

Cummings, R.G., and G.E. Morris, "Economic Modeling of Electricity Production from Hot Dry Rock Geothermal Reservoirs: Methodology and Analysis," EPRI report EPRI-EA-630, Palo Alto, California (1979).

Dash, Z.V. (Ed.), "ICFT: An Initial Closed-Loop Flow Test of the Fenton Hill Phase II HDR Reservoir," Los Alamos National Laboratory report LA11498-HDR (1989).

Dash, Z.V., H.D. Murphy, R.L. Aamodt, R.G. Aguilar, D.W. Brown, D.A. Counce, H.N. Fisher,
C.O. Grigsby, H. Keppler, A.W. Laughlin, R.M. Potter, J.W. Tester, P.E. Trujillo, Jr., and G.A. Zyvolski, "Hot Dry Rock Geothermal Reservoir Testing 1978-1980," J. Volcan. Geother. Res. 15, 59-99 (1983).

DiPippo, R., "International Developments in Geothermal Power Production," Geothermal Resources Council Bulletin 9 (5), 8-19 (1988).

DiPippo, R., E.A. DiPippo, J. Kestin, and H.E. Khalifa, "Compound Hybrid Geothermal-Fossil Power Plants: Thermodynamic Analyses and Site-Specific Application," J. Eng. Power 103, 797-804 (1981).

Energy Information Administration, Petroleum Supply Monthly, December 1988, DOE/EIA-0109, USDOE, Wash., DC (1988).

Fehler, M., L. House, and H. Kaieda, "Determining Planes Along Which Earthquakes Occur. Method and Application to Earthquakes Accompanying Hydraulic Fracturing," J. Geophys. Res. 92, 9407-9414 (1987).

Hamilton, M.H., "Natural Gas, Nuclear Backers See Opportunity in 'Greenhouse' Concern," The Washington Post, B1-B2 (July 22, 1988).

Hot Dry Rock Assessment Panel (HDRAP), "Hot Dry Rock Geothermal Energy - Status of Exploration and Assessment," Report \#1 June 1977, Energy Research and Development Administration, ERDA-77-74, Washington, DC (1977).

Khalifa, H.E., "Hybrid Fossil/Geothermal Power Plants," Sourcebook on the Production of Electricity from Geothermal Energy, Ch. 4, J. Kestin et al. (Eds.), US Govt. Printing Office, Washington, DC, 471-503 (1980).

Kron, A., and G. Heiken, "Geothermal Gradient Map of the United States-Exclusive of Alaska and Hawaii," Los Alamos Scientific Laboratory map LA-8476-MAP (1980).

Lienau, P.J., G. Culver, and J.W. Lund, "Geothermal Direct Use Developments in the United States," report for the USDOE Idaho Operations Office under contract no. DE-FG07-87ID 12693 by GeoHeat Center, Oregon Institute of Technology, Klamath Falls, Oregon (1988). 
Lovins, A.B., L.H Lovins, F. Krause, and W. Bach, Least-Cost Energy - Solving the $\mathrm{CO}_{2}$ Problem (Brick House Publishing Co., Andover, Massachusetts, 1981).

Mathews, J.T., "Global Climate Change: Toward a Greenhouse Policy," Issues Sci. Technol. 3 (3), 57-68 (1987).

Moore, T., A. Dolbec, and D. Spencer, "Utility Turbopower for the 1990s, " EPRI J. 13 (3), 4-13 (1988).

Muffler, L.J.P. (Ed.) "Assessment of Geothermal Resources of the United States - 1978," US Geological Survey Circular 790 (1979).

Murphy, H.D., R. Drake, J.W. Tester, and G.A. Zyvoloski, "Economics of a 75-MWe Hot Dry Rock Geothermal Power Station Based upon the Design of the Phase II Reservoir at Fenton Hill," Los Alamos National Laboratory report LA-9241MS (1982).

National Research Council (NRC), Geothermal Energy Technology: Issues, R\&D Needs, and Cooperative Arrangements (National Academy Press, Washington, DC, 1987).

Roberts, V., "EPRI Economic Study," paper presented at the National Hot Dry Rock Program Development Council meeting on July 15, 1986, in Albuquerque, New Mexico (1986).

Rowley, J.C., "Worldwide Geothermal Resources," Handbook of Geothermal Energy, Ch. 2, L.M. Edwards et al. (Eds.) (Gulf Publishing, Houston, Texas, 1982).
Shepard, M., "The Politics of Climate," EPRI J. 14 (4), 4-15 (1988).

Shock, R.A.W., "An Economic Assessment of Hot Dry Rocks as an Energy Source for the UK," Energy Technology Support Unit report ETSU-R-34, UK DOE, Oxfordshire, UK (1986).

Smith, M.C., R.L. Aamodt, R.M. Potter, and D.W. Brown, "Manmade Geothermal Reservoirs," Proc. 2nd US Symposium on Geothermal Energy, San Francisco, California, 1781-1787 (1975).

Spencer, D.F., "Utility Turbopower in the 1990s," EPRI J. 13 (3), 3 (1988).

Tester, J.W., "Energy Conversion and Economic Issues for Geothermal Energy," Handbook of Geothermal Energy, Ch. 10, L.M. Edwards et al. (Eds.) (Gulf Publishing Co., Houston, Texas, 1982).

Tester, J.W., G.E. Morris, R.G. Cummings, and R.L. Bivins, "Electricity from Hot Dry Rock Geothermal Energy: Technical and Economic Issues," Los Alamos Scientific Laboratory report LA7603-MS (1979).

Whetten, J., B. Dennis, D. Dreesen, L. House, H. Murphy, B. Robinson, and M. Smith, "The US Hot Dry Rock Project," Los Alamos National Laboratory document LA-UR-86-1109, presented at EEC/US Workshop on Geothermal Hot Dry Rock, Brussels, Belgium (May 28-30, 1986).

White, D.F., and D.L. Williams (Eds.), "Assessment of Geothermal Resources of the United States1975," US Geological Survey Circular 726 (1975). 